\title{
Optimal I nterest Rate Stabilization in a Basic Sticky-Price Model
}

\section{Matthias Paustian* \\ Christian Stoltenberg**}

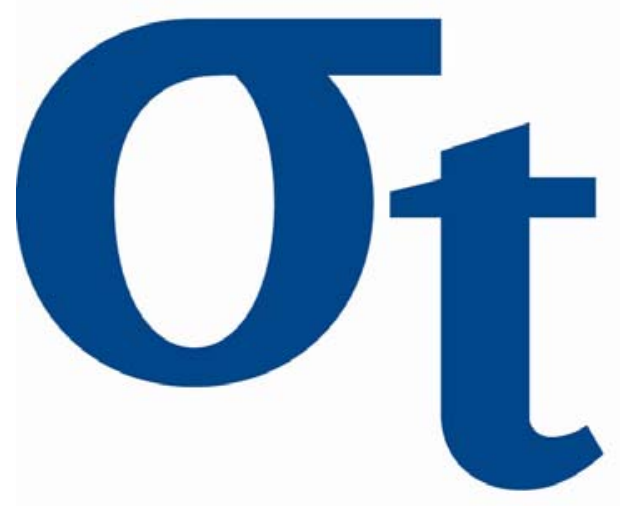

O)

$\nabla$

6

* Bowling Green State University, Department of Economics, Bowling Green, USA

** Department of Economics, Humboldt-Universität zu Berlin, Germany

This research was supported by the Deutsche Forschungsgemeinschaft through the SFB 649 "Economic Risk". 


\title{
Optimal Interest Rate Stabilization in A BASIC STICKY-PRICE MODEL*
}

\author{
Matthias Paustian, ${ }^{\dagger}$ Christian Stoltenberg ${ }^{\ddagger}$
}

September 2006

\begin{abstract}
This paper studies optimal monetary policy with the nominal interest rate as the single policy instrument in an economy, where firms set prices in a staggered way without indexation and real money balances contribute separately to households' utility. The optimal deterministic steady state under commitment is the Friedman rule - even if the importance assigned to the utility of money is small relative to consumption and leisure. We approximate the model around the optimal steady state as the long-run policy target. Optimal monetary policy is characterized by stabilization of the nominal interest rate instead of inflation stabilization as the predominant principle.
\end{abstract}

JEL classification: E32, E52, E58.

Keywords: Optimal monetary policy, commitment, timeless perspective, optimal steady state, staggered price setting, monetary friction, Friedman's rule.

*We are especially thankful to Tim Fuerst, Harald Uhlig, Juergen von Hagen and Andreas Schabert. Further, we would like to thank Dirk Krüger, Michael Burda, Marco Airaudo and Mirko Wiederholt for suggestions and comments. This research was supported by the Deutsche Forschungsgemeinschaft through the SFB 649 "Economic Risk". Earlier versions of this paper circulated under the title "The Inactiveness of Central Banks: An Issue of Optimality?".

${ }^{\dagger}$ Bowling Green State University, Department of Economics, Bowling Green, OH 43403, USA, email: paustim@cba.bgsu.edu, fax: +1 419 372-1557, tel: +1 419 372-3491.

${ }^{\ddagger}$ Humboldt University Berlin, Department of Economics, D-10178 Berlin, Germany, email: stoltenb@wiwi.hu-berlin.de, fax: +49 30 2093-5934, tel: +49/30/2093-5935. 


\section{Introduction}

What is the primary aim of optimal monetary policy? In the existing literature there are two major views that deliver opposite recommendations for the optimal conduct of monetary policy in the short and in the long run. The first branch goes back to Friedman (1969) and evaluates monetary policy in the long run with fully flexible prices and under perfect competition. In order to equate the private opportunity costs for holding money to the zero social costs to produce it, the nominal interest rate should be zero. The other view considers optimal monetary policy in the short run in the presence of nominal rigidities and imperfect competition (e.g. Woodford, 2003a, ch.6-8; Benigno and Woodford, 2005; Khan et al., 2003; Schmitt-Grohé and Uribe, 2004, 2005). A key feature of this literature is that the authors consider small fluctuations around the (almost) zero inflation steady state, implying that optimal policy nearly completely offsets the distortions due to price dispersion - even in the presence of a monetary friction. The predominant principle is inflation stabilization, while the nominal interest rate should adjust relatively freely to support this principle (Woodford, 2003a).

In this paper we revisit the issue of optimal monetary policy in a sticky price model in the presence of a transaction friction. The foremost contribution is to challenge the conventional view that the Friedman rule loses out to the goal of price stability once price stickiness is introduced. We show that the widely used money-in-the utility function model (MIU) implies that Friedman's rule is optimal even when large amounts of price stickiness are present. This is in contrast to the key message of papers such as Woodford (2003a), Khan, King and Wolman (2003) and Schmitt-Grohé and Uribe $(2004,2005)$ and others. Second, we find that the primary aim of optimal policy in the short run is to stabilize the nominal interest rate instead of inflation.

Our analysis is set in a dynamic stochastic general equilibrium model with imperfect competition and Calvo's staggered price setting (1983) without indexation. A trans- 
action friction is introduced via the textbook money-in-the-utility-function approach (Sidrauski, 1967; Woodford, 2003a; Walsh, 2003) with consumption and real money balances entering in a separable way. Assuming that the government has access to lump-sum taxes, we focus on optimal monetary policy that relies on the risk-free nominal interest rate as the single policy instrument. Since we allow for the existence of an output subsidy that offsets the distortion created by monopolistic competition, the policy maker faces two distortions: price dispersion due to staggered price setting calls for an optimal inflation of zero, implying costs of money holdings. However, the monetary distortion can only be offset by setting the nominal interest rate to zero.

We determine the optimal deterministic steady state under commitment as the optimal long-run target of monetary policy. ${ }^{1}$ Remarkably, we find that even for very low values for the weight of money in the utility function relative to consumption and leisure, it is optimal to fully offset the monetary distortion and to allow for a small degree of price dispersion. I.e. the Friedman rule is optimal even in the presence of Calvo-style staggered price setting. This result holds for wide a range of parameter values including low weights for real money balances in the utility function. To understand this finding, note that the welfare cost of price dispersion arising from long-run deflation required by the Friedman rule is small relative to the loss from a positive nominal interest rate. While the welfare loss due to price dispersion hinges primarily on the frequency of price adjustment, the utility losses of a positive interest rate crucially depends on the sensitivity of money demand to the nominal interest rate. In an MIU framework, the latter increases strongly as interest rates fall. Thereby, the taxation of money holdings via a positive interest rate becomes suboptimal.

We linearize the model around the optimal steady state under commitment as the long-run optimal policy target and derive a quadratic approximation to the utility of

\footnotetext{
${ }^{1}$ To be more precise, we consider policies that are optimal from a timeless perspective (Woodford, $2003 a)$.
} 
the representative household as the objective of the central bank. This welfare based loss-function depends on three arguments: the unconditional variances of inflation, the output gap, and on the variance of the nominal interest rate. While the weight for the variation in the output gap relative to inflation depends exclusively on deep parameters, the relative weight for interest rate variability hinges on steady state values, too. Remarkably, the preference to stabilize fluctuations in the nominal interest rate increases as optimal inflation moves towards Friedman's rule of deflation. This increase is primarily driven by the rise in the interest elasticity of money demand. Correspondingly, the importance to account for monetary frictions depends upon the steady state chosen for approximation: The long-run optimal policy is key for optimal policy reactions in the short run. Since we approximate our model around a steady state implied by the Friedman rule, the primary goal of optimal monetary policy is to stabilize variations in the interest rate rather than in inflation. Given the high weight attached to interest rate stabilization, optimal monetary policy requires abstaining from fluctuations in the nominal interest rate. Instead, the nominal interest rate is literally fixed in response to various kinds of disturbances. In that sense, the observation that central banks keep the main refinancing rate constant over a long time horizon, e.g. the European Central Bank from June until December 2005, can be interpreted as optimal policy according to Friedman's rule - even if the state of the economy has changed.

We show that choosing a long-run deflation target according to the Friedman rule does not generally undermine the central banks ability to stabilize the welfare relevant fluctuations around that target. On the contrary, the welfare loss arising from fluctuations around the Friedman steady state can be lower than the loss arising from fluctuations around the zero inflation steady state. Overall, we find support for the Friedman rule even in case of a reasonable amount of nominal rigidity due to staggered price setting a la Calvo: The Friedman rule yields higher steady state utility and can 
also improve welfare effects of fluctuations around the steady state compared to price stability.

Regarding the lower bound on the nominal interest rate, we find that this is not a concern for central banks in our model. We assume that the zero bound on interest rates is not binding in expectations, i.e. the average gross nominal interest rate must be at least slightly larger than unity. While this assumption does not exclude the possibility of an occasionally binding constraint, the probability for this to occur is virtually zero. The standard deviation of the nominal interest rate under optimal policy is so small relative to the buffer between the steady state nominal rate and unity, that the lower bound essentially never becomes binding.

\section{Related Literature}

We now turn to the related literature. Most closely related to our paper is the work by Woodford (2003a, Chapter 6-7; Woodford, 2003b) and Schmitt-Grohé and Uribe (2005). Woodford also studies optimal monetary policy in a money-in-the-utility function framework with staggered price setting. In contrast to our analysis, the model is log-linearized around the zero inflation steady state without computing the optimal steady state in a first step. This approximation point then implies very different dynamics for the nominal interest rate. In his analysis, the nominal interest rate reacts rather sharply to shocks while the optimal path of inflation is relatively smooth over the cycle (see Woodford, 2003a: 504). Our contribution is to show that the optimal policy prescriptions differ substantially once one takes into account the interactions between long run and short run optimal policy.

Schmitt-Grohé and Uribe (2005) and Khan et al. (2003) also analyze optimal monetary policy with nominal rigidities and a monetary friction. These papers adopt a transaction technology approach to introducing money into the model. While Khan 
(2003) use a different time dependent pricing model than we do, the economic environment of Schmitt-Grohé and Uribe (2005) is more similar to our framework. They analyze a medium scale model with staggered price setting a la Calvo and various additional distortions. They find that the central bank should aim at price stability and stabilization of inflation as the main principle. The difference between their key finding and our results is explained as follows. The money-in-the-utility function approach we employ has different implications for money demand at low interest rates compared to the transactions technology in Schmitt-Grohé and Uribe. The MIU framework implies that the interest-elasticity of money demand increases by large amounts as the nominal interest rate approaches the lower bound. Correspondingly, welfare costs of positive interest rates increase substantially. This is not the case for their transaction cost technology. Our contribution is to show that both the degree of price dispersion, as well as the sensitivity of money demand with respect to nominal interest rates at low levels, are decisive for the conduct of optimal policy.

Methodologically, this paper differs from Khan et al. (2003) and Schmitt-Grohé (2005) by working with the linear-quadratic framework, rather than with the time invariant Ramsey approach. By showing that the weight on nominal interest stabilization in the loss function depends on the steady state values under control of the central bank, this approach helps to point out intuitively how long run optimal policy and short run stabilization policies are interrelated. In addition, the guiding principle of optimal monetary policy is directly transparent in the size of the relative weights to stabilize the nominal interest rate, inflation, and the output gap.

The remainder of this paper proceeds as follows: in section 2 we set up the model. In section 3 we compute the optimal steady state under commitment and derive a quadratic approximation of the utility of the representative household. In section 4 we derive the optimal monetary policy responses in the short run for 2 policy regimes: 
the first one has Friedman's Rule, and the other one has zero inflation as its long-run target. The last section concludes.

\section{The model}

We consider an economy that consists of a continuum of infinitely lived households indexed with $j \in[0,1]$. It is assumed that households have identical initial asset endowments and identical preferences. Household $j$ acts as a monopolistic supplier of labor services $l_{j}$. Lower (upper) case letters denote real (nominal) variables. At the beginning of period $t$, households' financial wealth comprises money $M_{j t-1}$, a portfolio of state contingent claims on other households yielding a (random) payment $Z_{j t}$, and one period nominally non-state contingent government bonds $B_{j t-1}$ carried over from the previous period. Assuming complete financial markets let $q_{t, t+1}$ denote the period $t$ price of one unit of currency in a particular state of period $t+1$ normalized by the probability of occurrence of that state, conditional on the information available in period $t$. Then, the price of a random payoff $Z_{t+1}$ in period $t+1$ is given by $E_{t}\left[q_{t, t+1} Z_{j t+1}\right]$. The budget constraint of the representative household reads

$M_{j t}+B_{j t}+E_{t}\left[q_{t, t+1} Z_{j t+1}\right]+P_{t} c_{j t} \leq R_{t-1} B_{j t-1}+M_{j t-1}+Z_{j t}+P_{t} w_{j t} l_{j t}+\int_{0}^{1} D_{j i t} d i-P_{t} T_{t}$,

where $c_{t}$ denotes a Dixit-Stiglitz aggregate of consumption with elasticity of substitution $\theta, P_{t}$ the aggregate price level, $w_{j t}$ the real wage rate for labor services $l_{j t}$ of type $j$, $T_{t}$ a lump-sum tax, $R_{t}$ the gross nominal interest rate on government bonds, and $D_{i t}$ dividends of monopolistically competitive firms. Further, households have to fulfill the no-Ponzi game condition, $\lim _{i \rightarrow \infty} E_{t} q_{t, t+i}\left(M_{j t+i}+B_{j t+i}+Z_{j t+1+i}\right) \geq 0$. The objective 
of the representative household is

$$
E_{t_{0}} \sum_{t=t_{0}}^{\infty} \beta^{t}\left\{u\left(c_{j t}, \zeta_{t}\right)-v\left(l_{j t}\right)+z\left(M_{j t} / P_{t}\right)\right\}, \quad \beta \in(0,1)
$$

where $\beta$ denotes the subjective discount factor and $M_{j t} / P_{t}=m_{j t}$ end-of-period real money balances. Note that our specification of utility is consistent with recent findings by Andrés, López-Salido and Vallés (2006) for the Euro area and by Ireland (2004) for the US. They estimate the role of money for the business cycle of the Euro area and the US and find that preferences are separable between consumption and real money balances.

We assume that households' utility can be affected by a disturbance term $\zeta_{t}$ with mean 1 that can alter the utility of consumption. To avoid additional complexities, we set $u_{c \zeta}=u_{c}$ at the deterministic steady state. For each value of $\zeta$, the instantaneous utility function is assumed to be non-decreasing in consumption and real balances, decreasing in labor time, strictly concave, twice continuously differentiable, and to fulfill the Inada conditions. We assume that $z\left(m_{j t}\right)$ implies satiation in real money balances at a finite positive level. The derivatives $z_{m}, z_{m m}$ have finite limiting values as $m$ approaches the satiation level from below. In particular, the limiting value of $z_{m m}$ from below is negative (see Woodford, 2003a, Assumption 6.1).

Households are wage-setters supplying differentiated types of labor $l_{j}$ which are transformed into aggregate labor $l_{t}$ with $l_{t}^{\left(\epsilon_{t}-1\right) / \epsilon_{t}}=\int_{0}^{1} l_{j t}^{\left(\epsilon_{t}-1\right) / \epsilon_{t}} d j$. We assume that the elasticity of substitution between different types of labor, $\epsilon_{t}>1$, varies exogenously over time. The time variation in this markup parameter introduces a so called cost-push shock into the model that gives rise to a stabilization problem for the central bank. Cost minimization implies that the demand for differentiated labor services $l_{j t}$, is given by $l_{j t}=\left(w_{j t} / w_{t}\right)^{-\epsilon_{t}} l_{t}$, where the aggregate real wage rate $w_{t}$ is given by $w_{t}^{1-\epsilon_{t}}=\int_{0}^{1} w_{j t}^{1-\epsilon_{t}} d j$. 
Maximizing (2) subject to (1) and the no-Ponzi game condition for given initial values $M_{t_{0}-1}>0, Z_{0}, B_{t_{0}-1}$, and $R_{t_{0}-1} \geq 0$ leads to the following first order conditions for consumption, money, the real wage rate for labor type $j$, government bonds, and contingent claims:

$$
\begin{aligned}
& \lambda_{j t}=u_{c}\left(c_{j t}, \zeta_{t}\right), \quad v_{l}\left(l_{j t}\right)=w_{j t} \lambda_{j t} / \mu_{t}^{w}, \\
& \lambda_{j t}-z_{m}\left(m_{j t}\right)=\beta E_{t} \frac{\lambda_{j t+1}}{\pi_{j t+1}}, \quad q_{t, t+1}=\frac{\beta \lambda_{j t+1}}{\pi_{t+1} \lambda_{j t}}, \quad \lambda_{j t}=\beta R_{t} E_{t} \frac{\lambda_{j t+1}}{\pi_{t+1}}
\end{aligned}
$$

where $\lambda_{j t}$ denotes a Lagrange multiplier, $\pi_{t}$ the inflation rate $\pi_{t}=P_{t} / P_{t-1}$, and $\mu_{t}^{w}=$ $\epsilon_{t} /\left(\epsilon_{t}-1\right)$ the stochastic wage mark-up with mean $\bar{\mu}^{w}>1$. The first order condition for contingent claims holds for each state in period $t+1$, and determines the price of one unit of currency for a particular state at time $t+1$ normalized by the conditional probability of occurrence of that state in units of currency in period $t$. Arbitrage-freeness between government bonds and contingent claims requires $R_{t}=1 / E_{t} q_{t, t+1}$. The optimum is further characterized by the budget constraint (1) holding with equality and by the transversality condition $\lim _{i \rightarrow \infty} E_{t} \beta^{i} \lambda_{j t+i}\left(M_{j t+i}+B_{j t+i}+Z_{j t+1+i}\right) / P_{j t+i}=0$.

The final consumption good $Y_{t}$ is an aggregate of differentiated goods produced by monopolistically competitive firms indexed with $i \in[0,1]$ and defined as $y_{t}^{\frac{\theta-1}{\theta}}=$ $\int_{0}^{1} y_{i t}^{\frac{\theta-1}{\theta}} d i$, with $\theta>1$. Let $P_{i t}$ and $P_{t}$ denote the price of good $i$ set by firm $i$ and the price index for the final good. The demand for each differentiated good is $y_{i t}^{d}=\left(P_{i t} / P_{t}\right)^{-\theta} y_{t}$, with $P_{t}^{1-\theta}=\int_{0}^{1} P_{i t}^{1-\theta} d i$. A firm $i$ produces good $y_{i}$ using a technology that is linear in the labor bundle $l_{i t}=\left[\int_{0}^{1} l_{j i t}^{\left(\epsilon_{t}-1\right) / \epsilon_{t}} d j\right]^{\epsilon_{t} /\left(\epsilon_{t}-1\right)}: y_{i t}=a_{t} l_{i t}$, where $l_{t}=\int_{0}^{1} l_{i t} d i$ and $a_{t}$ is a productivity shock with mean 1 .

Labor demand satisfies: $m c_{i t}=w_{t} / a_{t}$, where $m c_{i t}=m c_{t}$ denotes real marginal costs independent of the quantity that is produced by the firm. 
We allow for a nominal rigidity in form of a staggered price setting as developed by Calvo (1983). Each period firms may reset their prices with the probability $1-\alpha$ independently of the time elapsed since the last price setting. The fraction $\alpha \in[0,1)$ of firms are assumed to keep their previous period's prices, $P_{i t}=P_{i t-1}$, i.e. indexation is absent. Firms are assumed to maximize their market value, which equals the expected sum of discounted dividends $E_{t} \sum_{T=t}^{\infty} q_{t, T} D_{i T}$, where $D_{i t} \equiv P_{i t} y_{i t}(1-\tau)-P_{t} m c_{t} y_{i t}$ and we used that firms also have access to contingent claims. Here, $\tau$ denotes an exogenous sales tax introduced to offset the inefficiency of steady state output due to markup pricing (Rotemberg and Woodford, 1999). In each period a measure $1-\alpha$ of randomly selected firms set new prices $\widetilde{P}_{i t}$ as the solution to $\max _{\widetilde{P}_{i t}} E_{t} \sum_{T=t}^{\infty} \alpha^{T-t} q_{t, T}\left(\widetilde{P}_{i t} y_{i T}(1-\right.$ $\left.\tau)-P_{T} m c_{T} y_{i T}\right)$, s.t. $y_{i T}=\left(\widetilde{P}_{i t}\right)^{-\theta} P_{T}^{\theta} y_{T}$. The first order condition for the price of re-optimizing producers is for $\alpha>0$ given by

$$
\frac{\widetilde{P}_{i t}}{P_{t}}=\frac{\theta}{\theta-1} \frac{F_{t}}{K_{t}}
$$

where $K_{t}$ and $F_{t}$ are given by the following expressions:

$$
F_{t}=E_{t} \sum_{T=t}^{\infty}(\alpha \beta)^{T-t} u_{c}\left(c_{T}, \zeta_{T}^{(1)}\right) y_{T}\left(\frac{P_{T}}{P_{t}}\right)^{\theta} m c_{T}
$$

and

$$
K_{t}=E_{t} \sum_{T=t}^{\infty}(\alpha \beta)^{T-t} u_{c}\left(c_{T}, \zeta_{T}^{(1)}\right)(1-\tau) y_{T}\left(\frac{P_{T}}{P_{t}}\right)^{\theta-1}
$$

Aggregate output is given by $y_{t}=l_{t} / \Delta_{t}$, where $\Delta_{t}=\int_{0}^{1}\left(P_{i t} / P_{t}\right)^{-\theta} d i \geq 1$ and thus $\Delta_{t}=(1-\alpha)\left(\widetilde{P}_{t} / P_{t}\right)^{-\theta}+\alpha \pi_{t}^{\theta} \Delta_{t-1}$. The dispersion measure $\Delta_{t}$ captures the welfare decreasing effects of staggered price setting. If prices are flexible, $\alpha=0$, then the first order condition for the optimal price of the differentiated good reads: $m c_{t}=(1-\tau) \frac{\theta-1}{\theta}$. The public sector consists of a fiscal and a monetary authority. The central bank as 
the monetary authority is assumed to control the short-term interest rate $R_{t}$. The fiscal authority issues risk-free one period bonds, has to finance exogenous government expenditures $P_{t} G_{t}$, receives lump-sum taxes from households, transfers from the monetary authority, and tax-income from an exogenous given constant sales tax $\tau$, such that the consolidated budget constraint reads: $R_{t-1} B_{t-1}+M_{t-1}+P_{t} G_{t}=M_{t}+B_{t}+P_{t} T_{t}+\int_{0}^{1} P_{i t} y_{i t} \tau d i$. The exogenous government expenditures $G_{t}$ evolve around a mean $\bar{G}$, which is restricted to be a constant fraction of output, $\bar{G}=\bar{y}(1-s c)$. We assume that tax policy guarantees government solvency, i.e., ensures $\lim _{i \rightarrow \infty}\left(M_{t+i}+B_{t+i}\right) \prod_{v=1}^{i} R_{t+v}^{-1}=0$. Due to the existence of the lump-sum tax, we consider only the demand effect of government expenditures and focus exclusively on optimal monetary policy.

We collect the exogenous disturbances in the vector $\xi_{t}=\left[\zeta_{t}, a_{t}, G_{t}, \mu_{t}^{w}\right]$. It is assumed that the percentage deviation of each of the elements of the vector from their means evolve according to autonomous $\mathrm{AR}(1)$-processes with autocorrelation coefficients $\rho_{\zeta}, \rho_{a}, \rho_{G}, \rho_{\mu} \in[0,1)$. The innovations are assumed to be i.i.d..

The recursive equilibrium is defined as follows:

Definition 1 Given initial values, $M_{t_{0}-1}>0, P_{t_{0}-1}>0$ and $\Delta_{t_{0}-1} \geq 0$, a monetary policy and a ricardian fiscal policy $T_{t} \forall t \geq t_{0}$, a sales tax $\tau$, a rational expectations equilibrium (REE) for $R_{t} \geq 1$, is a set of sequences $\left\{y_{t}, c_{t}, l_{t}, m c_{t}, \Delta_{t}, P_{t}, \widetilde{P}_{i t}, m_{t}\right.$, $\left.m c_{t}, R_{t}\right\}_{t=t_{0}}^{\infty}$ satisfying the firms' first order condition $m c_{t}=w_{t} / a_{t}$, (5) with $\widetilde{P}_{i t}=$ $\widetilde{P}_{t}$, and $P_{t}^{1-\theta}=\alpha P_{t-1}^{1-\theta}+(1-\alpha) \widetilde{P}_{t}^{1-\theta}$, the households' first order conditions $u_{c}\left(y_{t}-\right.$ $\left.G_{t}, \zeta_{t}\right) w_{t}=v_{l}\left(l_{t}\right) \mu_{t}^{w}, u_{c}\left(y_{t}-G_{t}, \zeta_{t}\right) / P_{t}=\beta R_{t} E_{t} u_{c}\left(y_{t+1}-G_{t+1}, \zeta_{t+1}\right) / P_{t+1}, z_{m}\left(m_{t}\right)=$ $u_{c}\left(y_{t}-G_{t}, \zeta_{t}\right)\left(R_{t}-1\right) / R_{t}$, the aggregate resource constraint $y_{t}=l_{t} / \Delta_{t}$, clearing of the goods market $c_{t}+G_{t}=y_{t}$ and the transversality condition, for $\left\{\xi_{t}\right\}_{t=t_{0}}^{\infty}$.

We will address the issue of the lower bound in the following way. First, we compute the optimal steady state under the assumption that the expected nominal interest rate 
is positive. This is equivalent to a postulated expected inflation rate slightly larger than the discount factor, $E \pi_{t} \geq \beta+\epsilon$, with $\epsilon$ as a small positive scalar. Then we approximate our model around the optimal steady state given a value for $\epsilon$ and solve for the optimal policy outcome in the short run. Computing the unconditional variance for the nominal interest rate allows us to quantify the probability - in case of a shock

- that the nominal interest rate will reach the lower bound for a particular $\epsilon$-steady state.

\section{The Linear-Quadratic Optimal Policy Problem}

In a first step we compute the steady state that is "optimal from a timeless perspective" (Woodford, 2003a). I.e. we assume that at $t=t_{0}$ the central bank has been in charge for an infinite number of periods and that it respects commitments made in the past. This optimal steady state is our point of expansion for the log-linear approximation of the model's equilibrium conditions as well as for the derivation of the purely quadratic welfare measure. As we will see, long run and short run optimal policy are closely interrelated. Throughout we assume that the steady state is rendered efficient by an appropriate setting of the tax rate.

\subsection{The Optimal Steady State}

In this section we compute the optimal steady state under commitment. Since we consider policies that are optimal from a timeless perspective, the associated optimality conditions will be time invariant which marks the difference to a standard commitment approach. In particular, the optimality conditions in the initial period do not differ from those in later periods. The nonlinear optimization problem for the central bank is 
to maximize the utility of the representative household through choice of output, the dispersion measure, inflation, the nominal interest rate and the denominator $\left(K_{t}\right)$ and the numerator $\left(F_{t}\right)$ of the optimal pricing condition for the firm:

$$
\max \mathcal{L}=E_{t_{0}} \sum_{t=t_{0}}^{\infty} \beta^{t-t_{0}}\left\{u\left(y_{t}-G_{t}, \zeta_{t}\right)-v\left(\Delta_{t} y_{t} / a_{t}\right)+z\left(m\left(R_{t}, y_{t}-G_{t}, \zeta_{t}\right)\right)\right\}
$$

subject to the firms' optimal pricing condition, the recursive formulation of the functions $K_{t}$ and $F_{t}$, the evolution of the dispersion measures and the euler equation:

$$
\begin{gathered}
\rho\left(\pi_{t}\right)^{\frac{1}{1-\theta}} K_{t}=\frac{\theta}{\theta-1} F_{t} \\
K_{t}=u_{c}\left(y_{t}-G_{t}, \zeta_{t}\right)(1-\tau) y_{t}+\beta \alpha E_{t} K_{t+1} \pi_{t+1}^{\theta-1} \\
F_{t}=v_{l}\left(y_{t} \Delta_{t} / a_{t}\right) y_{t} \mu_{t}^{w}+\alpha \beta E_{t} F_{t+1} \pi_{t+1}^{\theta} \\
\Delta_{t}=(1-\alpha) \rho\left(\pi_{t}\right)^{\frac{\theta}{\theta-1}}+\alpha \Delta_{t-1} \pi_{t}^{\theta}
\end{gathered}
$$

and

$$
u_{c}\left(y_{t}-G_{t}, \zeta_{t}\right)=\beta R_{t} E_{t} \frac{u_{c}\left(y_{t+1}-G_{t+1}, \zeta_{t+1}\right)}{\pi_{t+1}},
$$

with $\rho\left(\pi_{t}\right) \equiv\left(1-\alpha \pi_{t}^{\theta-1}\right)(1-\alpha)^{-1}$. In addition, optimality from a timeless perspective requires a certain degree of of prior commitment. The optimum can be described by the constraints (9)-(13) and the first order necessary conditions for the choice of $y_{t}, \Delta_{t}$, $K_{t}, F_{t}, R_{t}$ and $\pi_{t}$ (details see appendix 6.1).

To simplify the analysis and to solve for the optimal steady numerically, we assume that households' utility is given by the usual CRRA specification:

$$
\frac{c^{1-\sigma_{c}}}{1-\sigma_{c}}-a_{2} \frac{l^{1+\omega}}{1+\omega}+a_{1} \frac{m^{1-\sigma_{m}}}{1-\sigma_{m}}
$$


$\sigma_{c}, \sigma_{m}$ positive and $\omega$ non-negative. Here, $a_{1} \geq 0$ denotes the weight for the utility stemming from real money balances relative to the utility of consumption and $a_{2}$ the corresponding relative weight for the disutility of labor. ${ }^{2}$ As mentioned above we assume that the zero-bound on the interest rate is not binding in expectations. In the deterministic steady state this is equivalent to assuming that expected inflation is at least $E \pi_{t} \geq \beta+\epsilon$. The reason for this assumption is twofold. Economically, the resulting buffer allows the central bank to adjust its instrument downward as response to a shock (at least to a small amount). Technically, the CRRA preferences do not display a satiation point for real money balances at a finite level. However, by imposing a lower bound on the nominal interest defined by the small parameter $\epsilon>0$, real money balances are still bounded - even if inflation equals $\beta+\epsilon$. The derivatives $z_{m}$ and $z_{m m}$ exhibit finite limiting values as real money balances approach the level associated with the $\epsilon$ lower bound from below.

\begin{tabular}{ccccccccccc}
\hline$\sigma_{c}$ & $\sigma_{m}$ & $\omega$ & $\beta$ & $a_{1}$ & $a_{2}$ & $s c=\bar{c} / \bar{y}$ & $\bar{\mu}^{w}$ & $\theta$ & $\alpha$ & $\epsilon$ \\
\hline 2 & 2.5 & 0.5 & 0.99 & $1 / 99$ & 25 & 0.8 & $7 / 6$ & 6 & 0.66 & 0.0001 \\
\hline
\end{tabular}

Table 1: Baseline calibration

In our baseline calibration we set $\theta=6$ and $\alpha=0.66$, where the latter can be found for example in Walsh (2005) or Woodford (2003a). The parameter $a_{2}$ is set such that agents work $1 / 3$ of their available time in the steady state.

We calibrate the money demand block of our model to be in line with the existing literature and U.S. times series data. In particular, we set the annual interest semielasticity of money demand, $\partial \log m / \partial R=-\left[R(R-1) \sigma_{m}\right]^{-1}$ equal to -4.47 at an annual interest rate of $\mathrm{R}=1.083$. This is in line with Lucas (2000) and Woodford (2003a). In calibrating this elasticity we have assumed an average annual inflation rate of 4 per cent

\footnotetext{
${ }^{2}$ The first conditions and the constraints of the Ramsey problem in the deterministic steady state for the assumed CRRA preferences can be found in appendix 6.3.
} 
together with a real interest rate of 4.3 per cent such that $R=1.083$. It then follows that $\sigma_{m}=2.5$. Note that the semi-elasticity and the elasticity of money demand, $\eta_{R}(R) \equiv\left[(R-1) \sigma_{m}\right]^{-1}>0$, increases (in absolute terms) as interest rates decrease. ${ }^{3}$ We assume a degree of relative risk aversion $\sigma_{c}=2$. This implies an output elasticity of money demand $\sigma_{c} /\left(s_{c} \sigma_{m}\right)=1$. Furthermore, we set the parameter $a_{1}=1 / 99$ such that at a nominal interest rate of $R=1.083$ the annual ratio of $M 1$ over nominal GDP equals 0.2 . This value is consistent with postwar U.S. data and similar to the one used by Schmitt-Grohé and Uribe (2004, 2005).

Then the following numerical result for the $\epsilon$ steady state holds:

Result 1 (Optimal Steady State) If $a_{1} \geq 1 / 3513$ and the other parameters are given by the baseline calibration, optimal inflation in the deterministic steady state $\pi$ is $\beta+\epsilon=0.9901$. The associated optimal price dispersion $\bar{\Delta}$ is 1.0014 , while the optimal nominal interest rate $\bar{R}$ is $1.0001>1$.

Details of the computation can be found in appendix $6.2 .^{4}$ Under the baseline calibration, we find that the optimal steady value for inflation is the lower bound, $\pi=\beta+\epsilon$, i.e. it involves deflation. Correspondingly, the nominal interest rate is almost zero. We obtain this result even if when assuming a low weight for the utility of real money balances. Basically, Schmitt-Grohé and Uribe (2004, 2005) and Khan et al. (2003) find that the optimal inflation rate is close but not identical to unity, where the welfare function has slope zero, the interior solution (see Figure 1). In this steady state, the predominant aim of policy is to minimize price dispersion. However, if the weight assigned to the utility of real money balances is large enough - larger than $1 / 3513$ - this

\footnotetext{
${ }^{3}$ Note that this is not due to the fact that we use a separable MIU formulation. In case of a non-separable MIU specification, $u(c, m) ; u_{c m}>0$, which is equivalent to a shopping-time or real resource costs of transactions model (Feenstra, 1986), the corresponding elasticity becomes $\eta_{R}(R)=$ $\left[(R-1)\left(\sigma_{m}+\epsilon_{c m}\right)\right]^{-1}, \epsilon_{c m}=u_{c m} m / u_{c}$.

${ }^{4}$ To simplify the notation, steady state values in the following are denoted without a time subscript.
} 


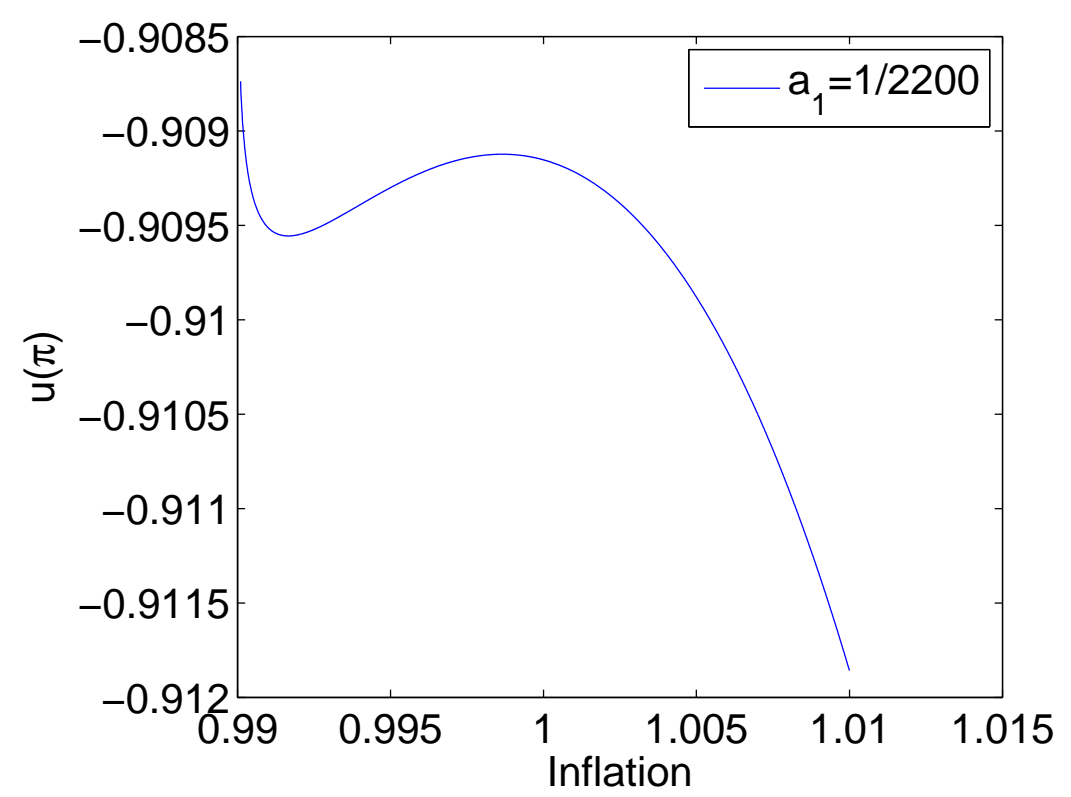

Figure 1: Welfare and Inflation in the steady state

optimum becomes a local maximum only, while the global optimum is the Friedman Rule.

Since $a_{1}$ is an unobserved preference parameter, it is difficult to assess whether the critical value $a_{1}=1 / 3513$ implies a large or small role for money in the utility function. However, the annual steady state ratio of $M 1$ over nominal GDP implied by this critical value is 0.048 . Hence, even if the importance of money in transactions - as measured by this ratio - falls by $76 \%$ from its baseline value of 0.2 , the Friedman rule would still be optimal. Therefore, the Friedman rule is optimal in our model even when money provides a very small flow of utility.

Why does the Friedman rule turn out to be optimal even when the importance of real money balances in the utility function is very low? Optimal monetary policy seeks to minimize two distortions created by price dispersion and the transaction friction, since the monopolistic distortion is eliminated by an output subsidy. ${ }^{5}$ Price dispersion

\footnotetext{
${ }^{5}$ The output subsidy of $\tau=1-\left(1-\alpha \beta \pi^{\theta-1}\right) \mu^{w} \theta \rho(\pi)^{1 /(\theta-1)}\left[\left(1-\alpha \beta \pi^{\theta}\right)(\theta-1)\right]^{-1}<0$ depends on steady state deflation. However, this feature does not favor the Friedman Rule in the steady state. If
} 
calls for an inflation rate of zero, while the monetary friction requires deflation. Correspondingly, we expect our optimal gross inflation rate to be found between $\beta$ and unity. First, while studies such as Kiley (2002) and Ascari (2004) have shown that relatively small amounts of trend inflation are associated with relatively large welfare costs under Calvo pricing, this is not the case for long run deflation. Figure 4 in the appendix shows that the price dispersion arising from long run deflation is relatively small. The second reason for the optimality of Friedman's rule is an adaption of a general principle of optimal taxation in public finance. Since the interest rate acts like a tax on money holdings, it should be low due to the fact that money demand is elastic with respect to interest under price stability.

While the choice for $\epsilon$ is arbitrary, our results are not very sensitive to the magnitude of $\epsilon$ (see Figure 5 in the appendix). The graph plots optimal annual inflation against the degree of price dispersion $\alpha$. Remarkably, our threshold levels for the optimality of Friedman's rule differ substantially from the results obtained by Schmitt-Grohé and Uribe (2005, Figure 1). While the Friedman rule in our model is optimal until the degree of price dispersion is below 0.81, Schmitt-Grohé and Uribe find a considerably lower breaking point of approximately 0.46 (see the vertical line in Figure 5), since the welfare costs of positive interest rates are lower in their transaction costs specification.

Which parameters influence the lower bound on $a_{1}$, i.e. the minimum weight for money in the utility function that renders the Friedman rule optimal? Put differently, which structural features work in favor for the Friedman rule and when does price dispersion become the main focus of monetary policy? To gain intuition for this question, we compare the outcomes of the Friedman rule and a zero inflation policy and derive an we were to apply the subsidy under zero-inflation, $\tau=1-\mu^{w} \theta /(\theta-1)$, the Friedman Rule would be optimal for even smaller relative weights of money in the utility function. The reason is as follows. First, note that steady state output is lower when the subsidy does not depend on trend deflation. Note further that the utility loss that households suffer due to a positive steady state price dispersion is weighted with the steady state output. 
analytical expression of the threshold for which the former dominates the latter policy.

Proposition 1 (Friedman's Rule and Zero Inflation) Assume that preferences are of the separable CRRA type and logarithmic, $\sigma_{m}=\sigma_{c}=1$, and $a_{2}=1$. Then the Friedman Rule steady state, $\pi_{F R}=\beta+\epsilon$, yields higher utility than the zero inflation steady state, $\pi_{Z E R O}=1$, if and only if

$$
a_{1}>\underline{a_{1}} \equiv \frac{\frac{\Delta_{F R}-1}{(1+\omega) s c}+\frac{\omega}{1+\omega} \ln \left[\Delta_{F R}\right]}{\ln \left[R_{F R} \eta_{R, F R}\left(R_{Z E R O} \eta_{R, Z E R O}\right)^{-1}\right]-\omega /(1+\omega) \ln \left[\Delta_{F R}\right]}
$$

with $\Delta_{F R}$ as the price dispersion associated with $\pi=\beta+\epsilon$ and $R_{F R} \eta_{R, F R}\left(R_{Z E R O} \eta_{R, Z E R O}\right)^{-1}=$ $(1-\beta)\left(1+\beta^{-1} \epsilon\right) / \beta^{-1} \epsilon$.

Proof see appendix 6.4.

$R_{Z E R O}=\beta^{-1}$ and $R_{F R}=1+\beta^{-1} \epsilon$ denote the gross nominal interest rate under zero inflation and Friedman's rule. Evidently, the Friedman rule performs better than a zero inflation regime, when the degree of price dispersion associated with the Friedman rule, $\Delta_{F R}$ is small. But at least equally important is the sensitivity of money demand with respect to interest rates under Friedman's rule, $\eta_{R, F R}$, compared to the corresponding elasticity if zero inflation applies, $\eta_{R, Z E R O}$. If these elasticities differ substantially, the amount and utility of real money balances in both regimes differs too. As will become clear below, this elasticity heavily influences the possible welfare losses due to positive interest rates. Furthermore, a large fraction of private consumption, sc, favors the Friedman rule. The intuition is as follows. Consider a value for $a_{1}$ such that the Friedman rule delivers the same steady state welfare as the zero inflation policy. If the fraction of government expenditures decreases, people have to work less since less output has to be produced. Due to price dispersion, people work more under the Friedman Rule, such that their marginal disutility of labor is always higher than under the zero inflation regime. Correspondingly, a one percent decrease in labor in both 
regimes leads to relatively larger utility gains in the Friedman Rule regime.

It is important to point out that the Friedman rule is optimal only under commitment, but never under discretion. The intuition for this result is that the nominal interest rate as the opportunity cost of money holdings depends on expected inflation. When the central bank acts under discretion, it cannot influence inflation expectations. Hence, the Friedman rule is not optimal under discretion. To see this more formally, consider the optimality condition of the planner's choice for inflation in the deterministic steady state under commitment:

$$
\begin{aligned}
& \lambda_{1} K \frac{\alpha}{1-\alpha} \pi^{\theta-2} \rho^{\frac{\theta}{1-\theta}}+\lambda_{2} \alpha K(\theta-1) \pi^{\theta-2}+\lambda_{3} \alpha F \theta \pi^{\theta-1} \\
& +\lambda_{4}\left[\theta \alpha \pi^{\theta-2} \rho^{\frac{1}{\theta-1}}-\alpha \theta \pi^{\theta-1} \Delta\right]-\lambda_{5} R \frac{u_{c}}{\pi^{2}} \doteq 0
\end{aligned}
$$

Here, the multipliers $\lambda_{4}>0$ and $\lambda_{5}>0$ measure the severeness of price dispersion and the transaction friction in terms of utility. A necessary requirement for the Friedman rule to qualify as an optimum is that (15) is non-positive for $\pi \rightarrow \beta$. Otherwise, it is always possible to increase welfare by increasing inflation. Therefore, a high value of $\lambda_{5}$ relative to $\lambda_{4}$ for all inflation rates between $\beta$ and 1 favors the lower bound as the optimum. While $\lambda_{4}$ is mainly driven by the degree of price stickyness $\alpha, \lambda_{5}$ crucially depends on the elasticity of money demand with respect to the nominal interest rate, $\lambda_{5}=m z_{m} \eta_{R}$. In order not to distort behavior money holdings should not be taxed with positive interest rates if they are demanded elastically. Note that this reasoning is based on an expectation argument, which does not arise if the central bank acts under discretion. In that case, the central bank does not consider the impact of its actions on expected inflation. Hence, the first order condition for inflation

$$
\lambda_{1} K \frac{\alpha}{1-\alpha} \pi^{\theta-2} \rho^{\frac{\theta}{1-\theta}}+\lambda_{4}\left[\theta \alpha \pi^{\theta-2} \rho^{\frac{1}{\theta-1}}-\alpha \theta \pi^{\theta-1} \Delta\right]
$$


is not affected by the multiplier $\lambda_{5}$, i.e. by considerations that seek to eliminate the monetary distortion. Under discretion, the multiplier $\lambda_{5}$ does not appear since it is associated with future inflation. Correspondingly, the following proposition states that under discretion the Friedman rule is not optimal in our economy - independent of the size of the relative weight for the utility of real money balances.

Proposition 2 (Optimal Steady State under Discretion) Consider the optimization under discretion and suppose that $a_{1}$ and sc are finite. If the preferences are of the separable CRRA type and $\sigma_{c} s c^{-1} \geq 1$, then the Friedman Rule is not optimal in the deterministic steady state.

Proof see appendix 6.5.

In the following subsection we consider optimal monetary policy in the short run, assuming the baseline calibration, such that $\beta+\epsilon$ is the optimal inflation rate from a timeless perspective.

\subsection{Approximating the model around the optimal steady state}

The model is log-linearized around the optimal deterministic steady state $\pi=\beta+\epsilon<1$, i.e. under trend deflation and closely follows the approximation around trend inflation (Ascari, 2004). The rational expectations equilibrium for the log-linear-approximate model is then a set of sequences $\left\{\widehat{y}_{t}, \widehat{\pi}_{t}, \widehat{m}_{t}, \widehat{R}_{t}, \widehat{F}_{t}\right\}_{t=t_{0}}^{\infty}$ consistent with the following set of equilibrium conditions ${ }^{6}$

$$
\begin{gathered}
\sigma\left(E_{t} \widehat{y}_{t+1}-\widehat{y}_{t}+g_{t}-g_{t+1}\right)=\widehat{R}_{t}-\widehat{\pi}_{t+1} \\
\widehat{m}_{t}=\frac{\sigma}{\sigma_{m}}\left(\widehat{y}_{t}-g_{t}\right)-\eta_{R, F R} \widehat{R}_{t}
\end{gathered}
$$

\footnotetext{
${ }^{6}$ The derivation of the aggregate supply curve can be found in appendix 6.6.
} 


$$
\begin{gathered}
\widehat{\pi}_{t}=\beta E_{t} \widehat{\pi}_{t+1}+\kappa^{*}(\omega+\sigma)\left(\widehat{y}_{t}-\widehat{y}_{t}^{z}\right)+\frac{\kappa^{*}(\bar{\pi}-1)}{1-\alpha \beta \pi^{\theta}}\left[(\sigma-1) \widehat{y}_{t}+\widehat{F}_{t}\right] \\
\left.\widehat{F}_{t}=\left(1-\alpha \beta \pi^{\theta}\right)\left[(1+\omega) \widehat{y}_{t}+\widehat{\mu}_{t}^{w}-(1+\omega) \widehat{a}_{t}\right)\right]+\alpha \beta \pi^{\theta} E_{t}\left(\theta \widehat{\pi}_{t+1}+\widehat{F}_{t+1}\right),
\end{gathered}
$$

where $\eta_{R, F R}=\left[\sigma_{m}\left(R_{F R}-1\right)\right]^{-1}, s c=c / y, \sigma_{c}=-u_{c c} c / u_{c} c>0, \sigma=\sigma_{c} s c^{-1}, \omega=$

$v_{l l} l / v_{l}>0, g_{t}=\left(G_{t}-G\right) / y+\sigma^{-1} \widehat{\zeta}_{t}, \kappa^{*}=\left(1-\alpha \pi^{\theta-1}\right)\left(1-\beta \alpha \pi^{\theta}\right) /\left(\alpha \pi^{\theta}\right)$, disturbances are collected in $\widehat{y}_{t}^{z}=\left((1+\omega) \widehat{a}_{t}+\sigma g_{t}-\widehat{\mu}_{t}^{w}\right) /(\omega+\sigma), \sigma_{m}=-z_{m m}(\bar{m}) \bar{m} / z_{m}(\bar{m})>$ 0 , the transversality condition, for a monetary policy, a sequence $\left\{\widehat{\xi}_{t}\right\}_{t=t_{0}}^{\infty}$, and given initial values $M_{t_{0}-1}$ and $P_{t_{0}-1}$. Further $\widehat{z}_{t}$ denotes the percent deviation of a generic variable $z_{t}$ from its steady state value $z$. In addition we assume that the bounds on the fluctuations of the shock vector $\left\|\log \xi_{t}\right\|$ are sufficiently tight, such that $\xi_{t}$ remains in the neighborhood of its steady state value.

\subsection{The Quadratic Policy Objective}

In this section we derive a purely quadratic welfare measure for the utility of the average household as the relevant objective for optimal monetary policy in the short run.

We assume that the welfare-relevant objective is the expected and discounted average utility level of all households, which is given by

$$
U_{t_{o}} \equiv E_{t_{0}} \sum_{t=t_{0}}^{\infty} \beta^{t-t_{0}}\left\{u\left(c_{t}, \zeta_{t}\right)-\int_{0}^{1} v\left(l_{j t}\right) d j+z\left(M_{t} / P_{t}\right)\right\}
$$

Our aim is to derive a quadratic loss function that yields an accurate second order approximation of the average utility of all households. We seek to evaluate the approximated level of utility by using the log-linearized conditions (17)-(20) describing the competitive equilibrium - that is, we set up the familiar linear-quadratic optimal policy problem. A correct welfare ranking of alternative policies requires a second-order approximation of utility that involves no linear terms - at least in expectations (see 
Woodford, 2003a, ch.6).

The existence of a non-zero linear term in the utility approximation crucially relies on the distortions of the steady state output relative to the efficient output level as consequences of price and wage-setting power, distortionary taxation and trend deflation that are represented in $\phi$ :

$$
1-\phi=\rho(\pi)^{\frac{1}{1-\theta}}(1-\tau) \frac{\theta-1}{\mu^{w} \theta} \frac{1-\alpha \beta \pi^{\theta}}{1-\alpha \beta \pi^{\theta-1}}=\frac{v_{l}}{u_{c}}
$$

If this inefficiency gap is zero or only of first order in $\phi$, the linear term in the second order approximation vanishes. Following Rotemberg and Woodford (1997) we assume that the sales tax plays a role of an output subsidy that offsets exactly the steady state output distortion. Since we assume separability between consumption and real money balances, this implies that real balance effects do not contribute to this inefficiency measure.

As Carlstrom and Fuerst (2004) point out, the inclusion of money demand fundamentally changes optimal monetary policy responses even in case if one assumes - as we do - real balances do not effect the dynamic evolution of inflation and output in the competitive equilibrium. The reason is that variations in the nominal interest rate contribute to the relevant distortions the policy maker seeks to stabilize. As we will show below, the relative weight of variations in the interest rate that enters the welfare measure is substantially increased if we approximate around the optimal steady state. In the following proposition we derive a quadratic Taylor-series approximation to (21).

Proposition 3 (Quadratic Approximation to Utility) If the fluctuations in $y_{t}$ around $y, R_{t}$ around $R, \xi_{t}$ around $\xi, \pi_{t}$ around $\pi$ are small enough, $\pi$ and $\Delta$ are close enough to 1 , and if the steady state distortions $\phi$ vanish due to the existence of an appropriate 
subsidy $\tau$, the utility of the average household can be approximated by:

$$
U_{t_{0}}=-\Omega E_{t_{0}} \sum_{t=t_{0}}^{\infty} \beta^{t-t_{0}}\left[\lambda_{x}\left(\widehat{y}_{t}-\widehat{y}_{t}^{*}\right)^{2}+\widehat{\pi}_{t}^{2}+\lambda_{R} \widehat{R}_{t}^{2}\right]+\text { t.i.s.p. }+\mathcal{O}\left(\left\|\widehat{\xi}_{t}, \varsigma\right\|^{3}\right),
$$

where t.i.s.p. indicate terms independent of stabilization policy, $\kappa=(1-\alpha)(1-\alpha \beta)(\omega+$ $\sigma) / \alpha, \Omega=\frac{u_{c} y \theta(\omega+\sigma)}{2 \kappa}$,

$$
\begin{gathered}
\lambda_{x}=\frac{\kappa}{\theta}, \\
\lambda_{R}=\frac{\eta_{R, F R} \lambda_{x}}{v(\omega+\sigma)},
\end{gathered}
$$

and

$$
\widehat{y}_{t}^{*}=\frac{\sigma g_{t}+(1+\omega) \widehat{a}_{t}}{\omega+\sigma}
$$

where $v=y / m>0$.

Proof see appendix 6.7 .

Under the conditions given in proposition 3, the relative weights of inflation, output gap and the nominal interest rates correspond to the results in Woodford (2003a). Our analysis differs from Woodford (2003a), because the steady state values relate to the lower bound and no longer to price stability as in his analysis. A crucial feature for the validity of the quadratic approximation above is that price dispersion in the optimal deterministic steady state (involving deflation) is not too large. Since the dispersion measure is lower for deflation than for inflation (see Figure 4 in the appendix) this is more likely to be fulfilled when the model is approximated around a deflationary steady state. $^{7}$

Remarkably, only the weight to stabilize fluctuations in the nominal interest rate

\footnotetext{
${ }^{7}$ In addition, we checked the accuracy of the results by comparing them to the optimal solution implied by the procedure proposed by Khan et al. 2003. We thank Andrew Levin for providing us with the MATLAB codes that solve the Ramsey problem in Levin et. al. (2005)
} 
depends on steady state values, $v$ and $\eta_{R, F R}$. Since we approximate our model around the deterministic steady state consistent with the Friedman Rule, the value for the former is small and even more importantly the value for the latter is large, implying a high preference to stabilize variations in the opportunity costs to hold money: For $\pi \rightarrow \beta$, this preference becomes even infinitely large. Notably, the dependence of the stabilization weights on the approximation point is absent in cashless economies: The weights for inflation (1) and output gap stabilization $(\kappa / \theta)$ do not hinge on steady state values. To set up the optimal policy problem, we need to rewrite the relevant constraints, i.e. the Euler-equation, the law of motion for $\widehat{F}_{t}$ and the aggregate supply curve in terms of the welfare-relevant output gap, $x_{t}=\widehat{y}_{t}-\widehat{y}_{t}^{*}$ :

$$
\begin{gathered}
\widehat{R}_{t}=\widehat{\pi}_{t+1}+\sigma\left(E_{t} x_{t+1}-x_{t}\right)+n_{t} \\
\widehat{F}_{t}=\left(1-\alpha \beta \bar{\pi}^{\theta}\right)(1+\omega) x_{t}+u_{t}+\alpha \beta \bar{\pi}^{\theta} E_{t}\left(\theta \widehat{\pi}_{t+1}+\widehat{F}_{t+1}\right)
\end{gathered}
$$

and

$$
\widehat{\pi}_{t}=\beta E_{t} \widehat{\pi}_{t+1}+\eta_{4} x_{t}+\frac{\kappa^{*}(\bar{\pi}-1)}{1-\alpha \beta \bar{\pi}^{\theta}} \widehat{F}_{t}+s_{t}
$$

Here, $n_{t}, u_{t}, s_{t}$ denote linear combinations of the elements of $\widehat{\xi}_{t}$ and $\eta_{4}$ is a constant, which are defined in appendix 6.8. Note, that the money demand condition does not enter the set of relevant constraints of the policy problem. Nevertheless it influences the optimal decision via the quadratic loss function, in which it plays an important role in determining the relative weight of interest rate variations. 


\section{Optimal short-run policy from a timeless perspec- tive}

We are interested in the optimal policy from a timeless perspective (Woodford, 2003a) in a linear quadratic framework. We showed that the optimal policy in the long run is to follow the Friedman rule. In this section we consider the implications for optimal policy in the short run, if deflation - instead of zero inflation - is chosen as the optimal long target. In particular, we consider the optimal reaction to various kinds of disturbances and evaluate the resulting stabilization loss of both regimes.

\subsection{Optimal response to shocks}

This subsection discusses the optimal response to shocks in the economy. We present the impulse responses under optimal policy under commitment and distinguish two cases. In the first case, our set of equilibrium conditions is log-linearized around the optimal steady state in which the inflation rate is equal to $\beta+\epsilon$. In the second case, we follow the conventional procedure and approximate around a steady state of zero inflation. The choice of a point of expansion for the log-linearization affects both the loss function and equilibrium conditions. Log-linearizing round the Friedman rule increases the relative weight on the stabilization of the nominal interest rate and affects the coefficients in the Phillips curve.

When we log-linearize around the optimal steady state corresponding to the Friedman rule, we find that the central bank essentially keeps the nominal interest rate fixed in response to any of the shocks present in our model. Consider first the optimal response to a technology shock displayed in Figure 2.

A Taylor expansion around zero inflation suggests that central bank should lower the annualized nominal rate by roughly 12 basis points and then gradually return to 

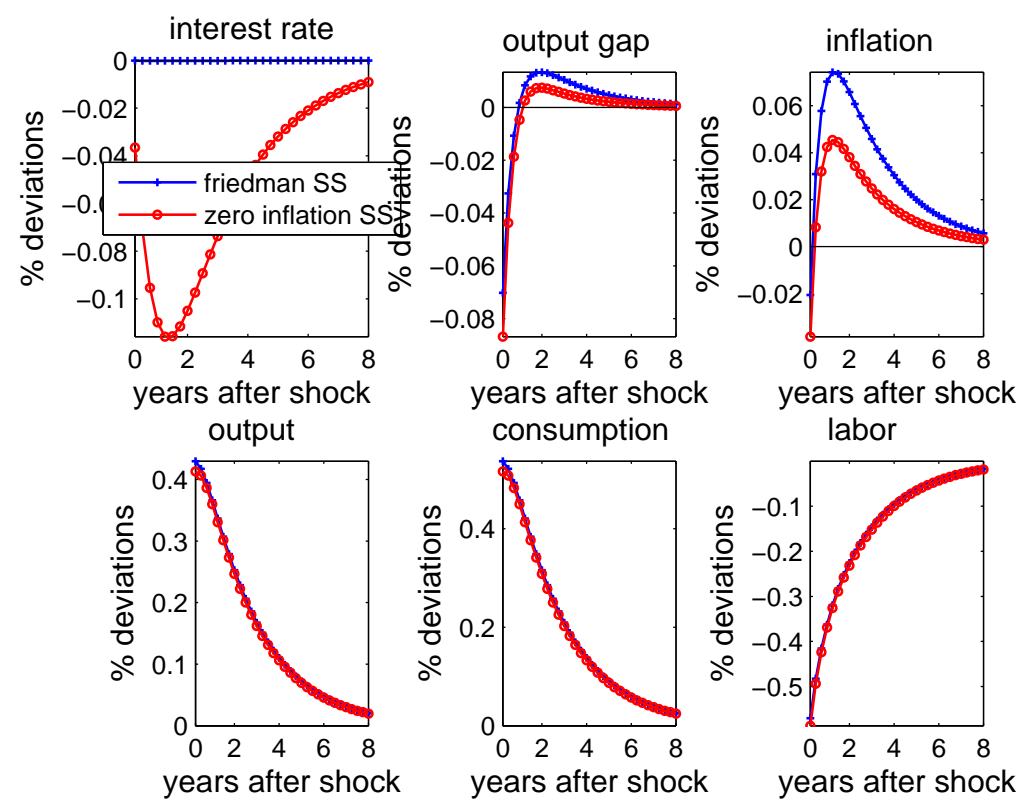

Figure 2: Responses to technology shock

the steady state. However, linearization around the Friedman rule implies that the nominal rate is literally fixed. In line with this finding, the approximation around the Friedman rule implies more volatile response of inflation and the output gap than what is suggested by linearization around the zero inflation steady state. A stronger stabilization of the nominal interest rate necessarily implies that the other arguments in the loss function can only be stabilized less.

Impulse responses to the other shocks deliver a similar message: Linearization around the Friedman steady state implies that the nominal interest rate is literally fixed. Inflation and output gap fluctuate by more than when the linearization is performed around the zero inflation steady state. The reason for why the interest rate does not respond under optimal policy is that stabilization of the interest rate is the main principle (see Table 2). Intuitively, the interest elasticity of money demand, $\left[\sigma_{m}(R-1)\right]^{-1}$ becomes very large as $R$ approaches its lower bound. For our baseline calibration this elasticity is roughly -4000 at $R=1+\epsilon$. Despite the fact that the marginal utility of 

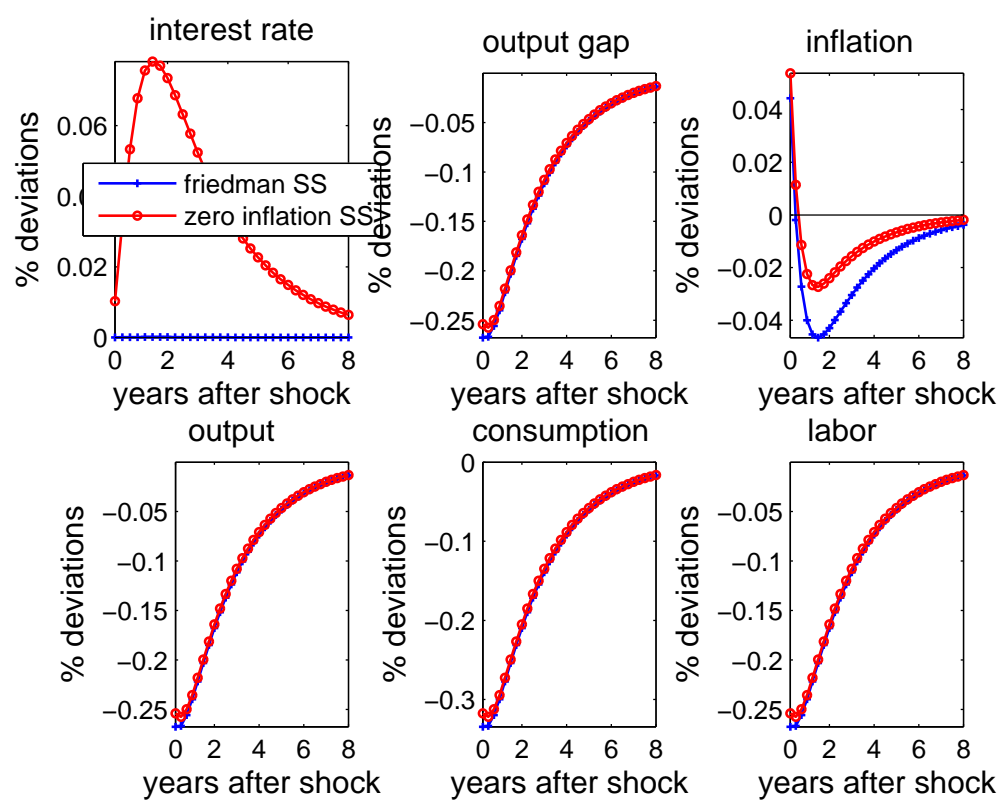

Figure 3: Responses to wage markup shock

real balances is close to zero (such that $v$ is small), this large elasticity explains why the central bank wishes to hold the nominal rate constant under the Friedman rule.

\subsection{Welfare Analysis}

In this subsection we compare the welfare implications of the two policy regimes the long run deflation target according to the Friedman rule vs. zero inflation as the long run target. Using (23) a second-order accurate approximation to the utility of the average household is given by:

$$
U_{t_{0}}=E_{t_{0}} \sum_{t=t_{0}}^{\infty} \beta^{t-t_{0}} U_{t} \approx \frac{1}{1-\beta} \bar{U}-\Omega E_{t_{0}} \sum_{t=t_{0}}^{\infty} \beta^{t-t_{0}} \lambda_{x}\left(\widehat{y}_{t}-\widehat{y}_{t}^{*}\right)^{2}+\widehat{\pi}_{t}^{2}+\lambda_{R} \widehat{R}_{t}^{2}
$$

The first part, the discounted steady state utility, is shown to be higher if the Friedman rule is optimal. The second part, the stabilization loss, that relates to the optimal policy reaction in the short run, is not necessarily lower under the Friedman rule regime than 
under zero inflation. Which of those two parts dominates depends on the calibration of the model, e.g. increasing the variances of the innovations amplifies the welfare loss due to short run fluctuations. In line with the spirit of the timeless perspective, we do not compute welfare conditional on a particular initial state vector at time $t_{0}$. Our short run stabilization loss is given by the discounted and weighted sum of unconditional variances:

$$
S L=-\frac{1}{1-\beta} \Omega\left\{\operatorname{var}(\widehat{\pi})+\lambda_{x} \operatorname{var}(x)+\lambda_{R} \operatorname{var}(\widehat{R})\right\}=-\frac{1}{1-\beta} \Omega L,
$$

Here $L$ is proportional to the unconditional expectation of period utility. In table 2 below we list the relative loss differences under the two policy regimes for a range of relative weights for the utility of real money balances given our baseline calibration for other parameters. For this purpose we calibrate the stochastic shock processes to match the standard deviations of real private consumption and government spending of U.S. data during the post-Volcker period. ${ }^{8}$ All exogenous processes are assumed to be autocorrelated with coefficient 0.9. We have chosen a standard deviation of the innovations to the taste shock of 0.0001 , for the markup shock 0.00015 , for the government spending shock 0.0075 and for the technology shock 0.0096 .

\footnotetext{
${ }^{8}$ The quarterly data is logged and detrended via the Hodrick-Prescott filter with a smoothing parameter of 10,000. The obtained standard deviation of private consumption is 0.0123 , for government expenditures we obtain 0.0172 .
} 


\begin{tabular}{ccccccc}
\hline$a_{1}$ & $\lambda_{R}^{Z E R O}$ & $\lambda_{R}^{F R}$ & $100 *\left(L_{Z E R O}-L_{F R}\right) / L_{F R}$ & $100 * d U / U$ & $\sigma_{F R}$ & $\sigma_{Z E R O}$ \\
\hline $1 / 20$ & 2.3426 & 1472 & 32.40 & 0.75 & 317 & 41 \\
$1 / 50$ & 1.6238 & 1020 & 20.36 & 0.49 & 220 & 31 \\
$1 / 99$ & 1.2355 & 777 & 10.24 & 0.35 & 167 & 25 \\
$1 / 150$ & 1.0463 & 658 & 3.72 & 0.28 & 142 & 23 \\
$1 / 189$ & 0.9539 & 600 & 0.00 & 0.25 & 129 & 21 \\
$1 / 250$ & 0.8530 & 536 & -4.55 & 0.21 & 116 & 20 \\
$1 / 500$ & 0.6464 & 406 & -15.97 & 0.14 & 88 & 17 \\
$1 / 1000$ & 0.4899 & 308 & -27.24 & 0.08 & 66 & 15 \\
\hline
\end{tabular}

Table 2: Welfare Analysis: $\epsilon=0.0001$

The results in Table 2 reveal that the larger the preference parameter of the households' for the Friedman rule steady state $a_{1}$ the larger is the willingness of the central bank to stabilize the nominal interest rate $\lambda_{R}^{F R}$. This implies that optimal long run and short run monetary policy are closely interrelated in case of a transaction friction ${ }^{9}$.

The resulting stabilization loss, when approximating around the Friedman rule steady state $L^{F R}$ is superior to the stabilization loss around zero inflation $L^{Z E R O}$ if $a_{1}$ is large enough. The (technical) intuition for this is a trade off effect between predictability and possible welfare losses in the neighborhood of the steady state of each regime. If the Friedman rule is the expansion point, then the reduced form involves 4 jump variables, $\widehat{R}_{t}, x_{t}, \widehat{\pi}_{t}$ and $\widehat{F}_{t}$, as well as 3 endogenous state variables, the multipliers on the relevant constraints, (27)-(29). If zero inflation is chosen as the approximation point, the reduced form does not involve $\widehat{F}_{t}$ and exhibits only the two multipliers associated with the aggregate supply curve and the euler equation as endogenous state variables. On the one hand, the state space is increased in the Friedman regime, implying higher prediction power by reducing the error variances of inflation, output gap and the nominal interest rate. ${ }^{10}$ On the other hand, however, possible welfare losses

\footnotetext{
${ }^{9}$ Table 3 in the appendix gives the corresponding results for $\epsilon=.000001$, i.e. if the assumed lower bound is closer to the zero bound.

${ }^{10}$ Note however, that the models are not structurally nested, since in the Friedman regime more
} 
in the neighborhood of the zero inflation steady state are lower, steady state utility is "flatter" around $\pi=1$ (see Figure 1). If the relative weight of real money balances decreases, the additional state variable loses prediction power, while possible welfare losses around the zero inflation steady state decrease. Intuitively, the prediction effect is larger, if the endogenous state variables carry the main relevant information from previous periods, i.e. if the disturbances are only weakly autocorrelated. While there is a cut-off value in terms of stabilization loss, overall utility composed of steady state utility minus stabilization loss, is higher under the Friedman rule than under zero inflation though the relative differences are small. The second but last column of Table 2 depicts this overall difference in utility under the Friedman regime minus the zero inflation regime expressed as percentages.

The entries $\sigma_{F R}$ and $\sigma_{Z E R O}$ shed light on how likely it is that the lower bound on the nominal interest rate binds if the economy fluctuates around the Friedman rule $\epsilon$ steady state or around price stability. We calculate the standard deviation of the nominal interest rate under the optimal policy implied by both policy regimes. The term $\sigma_{F R}$ then expresses the size of the interval from $R=1.0001$ to the lower bound $R=1$ in terms of this standard deviation. The entry $\sigma_{Z E R O}$ also expresses this interval in terms of standard deviations of the nominal rate, but now the approximation is computed around a zero inflation steady state. Hence, larger values for $\sigma_{F R}$ or for $\sigma_{Z E R O}$ imply that the lower bound is less likely to be binding. Note that our results imply a low probability that the nominal interest rate hits the lower bound, i.e. $R_{t}=1$. Even for a small relative weight of real money balances, $a_{1}=1 / 1000$, the resulting standard deviation for the nominal interest rate is small relative to $\epsilon$, such that a symmetric confidence interval around $R=1.0001$ of up to 66 standard deviations could be constructed until the lower bound is included. If we decrease $\epsilon$, i.e. if the assumed jump variables must be pinned down. 
lower bound moves closer to zero, the corresponding number of standard deviations increases to 418 (see table 3 in the appendix). This implies that the effect to stabilize

the nominal interest even more (higher relative weight $\lambda_{R}^{F R}$ ) dominates the effect of the smaller distance to the zero bound. Correspondingly, if zero inflation is chosen as the expansion point, the probability to hit the lower bound is even higher (see the last column).

\section{Conclusion}

We study optimal monetary policy in an economy without capital, where firms set prices in a staggered way without indexation and real money balances are assumed to provide utility. Accounting for a sizeable degree of nominal rigidity, the optimal deterministic steady state from a timeless perspective is to follow the Friedman rule, even if the importance assigned to the utility of money is small relative to consumption and leisure.

We approximate the model around the optimal steady state under commitment as the long-run policy target and derive a second order approximation to households' utility. Optimal interest rate policy is shown to abstain from reacting sharply to changes in the state of the economy. Instead of stabilizing inflation, the primary goal of the central bank is to stabilize fluctuations in the nominal interest rate. In that light, the well observed tendency of central banks to keep the main refinancing instrument literally fixed over a long time can be interpreted as optimal behavior according to Friedman's rule, even if the state of the economy has changed. Since optimal policy stabilizes fluctuations in interest to a large amount, the lower bound on the nominal interest rate is unlikely to be binding.

We stress that our model is not about direct and quantitative advice on optimal 
monetary policy. It is too stylized for this purpose. The foremost contribution of this paper is to challenge the conventional view that the Friedman rule loses out to the goal of price stability once price stickiness is introduced. We show that the widely used money-in-the utility function model implies that the Friedman rule is optimal even when large amounts of price stickiness are present. When the economy fluctuates around the Friedman rule steady state, central bankers should keep the nominal interest stable over the business cycle. This result is explained by the large interest elasticity of money demand that obtains in the MIU model when the nominal rate is close to zero. There is little empirical evidence on the behavior of money demand in the major industrialized countries for very low interest rates. This is unfortunate as the interest elasticity at low interest rates is a key difference between our MIU framework and the transactions technology employed in other papers that come to different policy prescriptions. Hence, future research on optimal policy in sticky price models benefits from a better understanding of money demand in such low interest rate environments.

\section{Appendix}

\subsection{The optimal deterministic state from a timeless perspec- tive}

The standard commitment approach would be to choose state contingent path for $\Delta_{t}, R_{t}, \pi_{t}$ and $y_{t}$ for each $t \geq t_{0}$, to maximize (8) for a given degree of initial price dispersion an initial nominal interest rate. Without any precommitment, this approach would suffer of time inconsistency. Woodford (2003) proposes a certain degree of initial commitment, to bring about the optimal equilibrium. In our case, we need to assume, 
that $F_{t_{0}}=F, K_{t_{0}}=K$ and $y_{t_{0}}=y$,i.e. the initial values for these variables are identical their optimal steady state values. The optimal deterministic steady state is a solution to the problem defined in the text, that involves constant values for all variables and each of the disturbances identical to their means. Basically we are looking for an initial degree of price dispersion $\Delta_{t_{0}-1}$ and an initial interest rate $R_{t_{0}-1}$, and precommitment $F_{t_{0}}=F, K_{t_{0}}=K$ and $y_{t_{0}}=y$, such that $R_{t}=R, \pi_{t}=\pi, F_{t}=F, K_{t}=K, y_{t}=y$, for each period, and $\Delta, R$ are equal to the initial price dispersion an the initial nominal interest rate. Using the time-invariant form for the Lagrangian, the first order necessary conditions with respect to $y_{t}, \Delta_{t}, K_{t}, F_{t}, R_{t}$ and $\pi_{t}$ for all $t \geq t_{0}$ are given by:

$$
\begin{gathered}
u_{c}(t)-\Delta_{t} v_{l}(t)+z_{m}(t) m_{c}(t)+\lambda_{2 t}(1-\tau)\left[u_{c c}(t) y_{t}+u_{c}(t)\right] \\
+\lambda_{3 t} \mu_{t}^{w}\left[v_{l l}(t) \Delta_{t} y_{t}+v_{l}(t)\right]-\lambda_{5 t} u_{c c}(t)+\lambda_{5 t-1} \frac{u_{c c}(t) R_{t-1}}{\pi_{t}} \doteq 0 \\
-y_{t} v_{l}(t)+\lambda_{3 t} v_{l l}(t) y_{t}^{2} \mu_{t}^{w}+\lambda_{4 t}-\lambda_{4 t+1} \beta \alpha \pi_{t+1}^{\theta} \doteq 0 \\
\lambda_{1 t} \rho(t)^{\frac{1}{1-\theta}}-\left[\lambda_{2 t}-\alpha \pi_{t}^{\theta-1} \lambda_{2 t-1}\right] \doteq 0 \\
-\frac{\theta}{\theta-1} \lambda_{1 t}-\left[\lambda_{3 t}-\alpha \pi_{t}^{\theta} \lambda_{3 t-1}\right] \\
z_{m}(t) m_{R}(t)+\lambda_{5 t} \beta \frac{u_{c}(t+1)}{\pi_{t+1}}
\end{gathered}
$$

and

$$
\begin{aligned}
& \lambda_{1 t} K_{t} \frac{\alpha}{1-\alpha} \pi_{t}^{\theta-2} \rho(t)^{\frac{\theta}{1-\theta}}+\lambda_{2 t-1} \alpha K_{t}(\theta-1) \pi_{t}^{\theta-2}+\lambda_{3 t-1} \alpha F_{t} \theta \pi_{t}^{\theta-1} \\
& +\lambda_{4 t}\left[\theta \alpha \pi_{t}^{\theta-2} \rho(t)^{\frac{1}{\theta-1}}-\alpha \theta \pi_{t}^{\theta-1} \Delta_{t-1}\right]-\lambda_{5 t-1} R_{t-1} \frac{u_{c}(t)}{\pi_{t}^{2}} \doteq 0
\end{aligned}
$$

Note that $\lambda_{2 t_{0}-1}, \lambda_{3 t_{0}}$ and $\lambda_{5 t_{0}-1}$ are the multipliers associated with the initial commitment. 


\subsection{Description of the numerical procedure to calculate the optimal steady state}

We solved for the optimal deterministic steady state numerically. Thereby we used the specific $C R R A$ utility function given in the text.

The procedure works in the following way: We solve for $y, R, F, K$ and $\Delta$ each as a function of steady state inflation exclusively - using the constraints (9)-(13). That is, for a given inflation rate, the values for the other variables are given by these functions. To check for the robustness of out results, we use two different procedures: The first one involves the exploitation of the first order conditions, the second one the direct evaluation of utility in the steady state. ${ }^{11}$

The first procedure is applied in the program stcommit.m. We use the values given by the constraints and solve for the lagrangian multipliers $\lambda_{1}-\lambda_{5}$ uniquely by exploiting the 5 first order conditions for output, interest, dispersion, $F$ and $K$. Then we use these values and substitute them in the first order condition for inflation, $f c(\pi)$, to check for optimality of the given inflation rate. Thereby several cases are possible. For example, if this condition is globally negative (positive) over the grid of steady state inflation rates, then the optimal inflation is the lower (upper) bound. If however, the first order condition crosses the zero line, the optimum can be an interior solution. Suppose that $f c(\pi)$ is positive at the lower bound, monotonically decreasing and crosses the inflation axis at some inflation rate, $\pi_{1} \in(\beta+\epsilon$, upper bound $)$. Then $\pi_{1}$ is the optimal inflation. If instead, $f c$ is negative at the lower bound, monotonically increasing and crosses the zero value for $\pi_{2}$, then $\pi_{2}$ can't be the optimum - either the lower bound or the upper bound is the optimum. Obviously - in principle - several cases are possible and even multiple solutions can arise. Once, the optimal inflation rate is found, the values for

\footnotetext{
${ }^{11}$ The MATLAB programs to compute the optimal steady state, and the Toolkit code to calculate the IRFs and the results in table 2 are available on request.
} 
the variables and the lagrangian multipliers are implied by the constraints or the first order conditions.

The program ssrand31. $m$ uses a direct evaluation of steady state utility by substituting for each given inflation rate, the values of output, interest, $F, K$ and dispersion into the utility function. Afterwards one maximizes over the resulting utility function and picks the optimal inflation rate and the optimal values for the variables are implied by the constraints of the optimal policy problem.

\subsection{Constraints and CRRA preferences in the steady state}

Suppose that the utility function is of the CRRA form. Given an output subsidy that renders the steady state efficient, constraints (9)-(13), and the money demand equation can be combined to solve for $\Delta, y, c, l, R$ and $m$ in terms of inflation.

$$
\Delta=\frac{(1-\alpha) \rho^{\frac{\theta}{\theta-1}}}{1-\alpha \pi^{\theta}}
$$

with $\rho=\left(1-\alpha \pi^{\theta-1}\right) /(1-\alpha)$,

$$
\begin{gathered}
y=\left[\frac{1}{a_{2} \Delta^{\omega} s c^{\sigma_{c}}}\right]^{\frac{1}{\sigma_{c}+\omega}}, \\
c=y s c, \\
l=y \Delta \\
R=\frac{\pi}{\beta}, \\
m=\left[R /(R-1) y^{\sigma_{c}} a_{1} s c^{\sigma_{c}}\right]^{1 / \sigma_{m}} .
\end{gathered}
$$




\subsection{Proof proposition 1}

Consider first the steady state utility if the inflation rate is zero. Correspondingly, gross inflation and price dispersion are 1 , such that $y_{Z E R O}=l_{Z E R O}$. Using (39)(43), one can compute $y_{Z E R O}=1 / s c^{1 /(1+\omega)}=l_{Z E R O}, c_{Z E R O}=s c^{\omega /(1+\omega)}$ and $m_{Z E R O}=$ $R_{Z E R O} \eta_{R, Z E R O} a_{1} s c^{\omega /(1+\omega)}$. Then the period steady state utility of the average household is given by

$$
u_{Z E R O}=\left(1+a_{1}\right) \frac{\omega}{1+\omega} \ln (s c)-\frac{1}{(1+\omega) s c}-a_{1} \ln (1-\beta)+a_{1} \ln \left(a_{1}\right) .
$$

If $\pi=\beta+\epsilon$, then price dispersion is $\Delta_{F R}>1$, and output equals $y_{F R}=1 /\left(s c \Delta_{F R}^{\omega}\right)^{1 /(1+\omega)}<$

$y_{Z E R O}$, while $l_{F R}=\left(\Delta_{F R} / s c\right)^{1 /(1+\omega)}>l_{Z E R O}$. Consumption and real money balances are then given by $c_{F R}=\left(s c / \Delta_{F R}\right)^{\omega /(1+\omega)}<c_{Z E R O}$ and $m_{F R}=R_{F R} \eta_{R, F R} a_{1}\left(s c / \Delta_{F R}\right)^{\omega /(1+\omega)}>$ $m_{Z E R O}$. In this case, the period steady state utility is

$u_{F R}=\left(1+a_{1}\right) \frac{\omega}{1+\omega} \ln (s c)-\frac{\omega}{1+\omega}\left(1+a_{1}\right) \ln \left(\Delta_{F R}\right)-\frac{\Delta_{F R}}{(1+\omega) s c}+a_{1} \ln \left(\frac{1+\beta^{-1} \epsilon}{\beta^{-1} \epsilon}\right)+a_{1} \ln \left(a_{1}\right)$.

Comparing (44) and (45), the Friedman rule yields higher utility as long as $a_{1}>\underline{a_{1}}$.

\subsection{Proof proposition 2}

This proof is per contradiction. If the Friedman rule is optimal, then necessarily (16) must be non-positive. Under the assumed CRRA preferences, real money balances in the deterministic steady state are given by (43), implying that they converge to infinity for $R \rightarrow 1$, given that $a_{1}$ and $s c$ are finite and positive. The lagrangian multiplier $\lambda_{5}=m /\left(R \sigma_{m}\right)$ converges to infinity, too, while $\lambda_{1}$ under discretion is given by:

$$
\lambda_{1}=\frac{u_{c}-\Delta v_{l}+z_{m} m_{c}-\lambda_{5} u_{c c}}{-\rho^{1 /(1-\theta)}(1-\tau)\left(u_{c c} y+u_{c}\right)+\theta /(\theta-1) \bar{\mu}^{w}\left(v_{l l} \Delta y+v_{l}\right)} .
$$


This multiplier is positive for $\lambda_{5} \rightarrow \infty$ and $\sigma s c^{-1} \geq 1$ such that $u_{c c} y+u_{c}<0$. Since $K=s c^{-\sigma_{c}}(1-\tau) y^{1-\sigma_{c}} /\left[1-\alpha \beta \pi^{\theta-1}\right]$ and $\rho=\left(1-\alpha \pi^{\theta-1)} /(1-\alpha)\right.$ are positive for $\pi<1$, the first expression in (16) is positive, implying, that the optimality of the Friedman rule requires the second expression to be negative. Note that the lagrangian multiplier

$$
\lambda_{4}=\frac{-\lambda_{3} y^{2} \bar{\mu}^{w} v_{l l}+v_{l} y}{1-\alpha \beta \pi^{\theta}}
$$

is positive, since $\lambda_{3}=-\theta /(\theta-1) \lambda_{1}<0$. Therefore, in order to qualify the Friedman rule as optimal under discretion

$$
\theta \alpha \pi^{\theta-2} \rho^{\frac{1}{\theta-1}}<\alpha \theta \pi^{\theta-1} \Delta
$$

must hold. This boils down to

$$
\begin{aligned}
\pi^{-1} \rho^{1 /(\theta-1)} & <\frac{(1-\alpha) \rho^{\theta /(\theta-1)}}{1-\alpha \pi^{\theta}} \\
\Longleftrightarrow \pi^{-1} & <\frac{\left(1-\alpha \pi^{\theta-1}\right)}{\left(1-\alpha \pi^{\theta}\right)} \\
\Longleftrightarrow \pi^{-1} & <1,
\end{aligned}
$$

which is a contradiction, since $\pi<1$ holds under the Friedman rule.

\subsection{Derivation of the aggregate supply curve in case of trend deflation}

The first order condition for firms is given by (5), which reads in loglinearized terms:

$$
\frac{\widehat{\widetilde{P}}_{i t}}{P_{t}}=\widehat{F}_{t}-\widehat{K}_{t} .
$$


Using the definition of the price level, $P_{i t} / P_{t}=\left[\left(1-\alpha \pi_{t}^{\theta-1}\right) /(1-\alpha)\right]^{1 /(1-\theta)}$, the left hand side of (47) can be approximated to first order with

$$
\frac{\alpha \bar{\pi}^{\theta-1}}{1-\alpha \bar{\pi}^{\theta-1}} \widehat{\pi}_{t}
$$

while the expression on the right-hand side can be approximated by (using the recursive form of $F_{t}$ and $\left.K_{t}\right)$ :

$$
\widehat{F}_{t}=\left(1-\alpha \beta \bar{\pi}^{\theta}\right)\left[u_{c}\left(\widehat{y_{t}-G_{t}}, \zeta_{t}\right)+\widehat{y}_{t}+\widehat{m c}_{t}\right]+\alpha \beta \bar{\pi}^{\theta} E_{t}\left(\theta \widehat{\pi}_{t+1}+\widehat{F}_{t+1}\right)
$$

and

$$
\left.\widehat{K}_{t}=\left(1-\alpha \beta \bar{\pi}^{\theta-1}\right)\left[u_{c}\left(\widehat{y_{t}-G_{t}}, \zeta_{t}\right)+\widehat{y}_{t}+\widehat{\left(1-\tau_{t}\right.}\right)\right]+\alpha \beta \bar{\pi}^{\theta-1} E_{t}\left((\theta-1) \widehat{\pi}_{t+1}+\widehat{K}_{t+1}\right) .
$$

Note that under trend deflation $\alpha \beta \bar{\pi}<1$, while convergence has to be assumed, if one approximates around trend inflation (Ascari, 2004). Therefore the difference $\widehat{F}_{t}-\widehat{K}_{t}$ is given by:

$$
\begin{aligned}
\widehat{F}_{t}-\widehat{K}_{t} & =\alpha \beta \bar{\pi}^{\theta-1}(\bar{\pi}-1) \theta E_{t} \widehat{\pi}_{t+1}+\alpha \beta \bar{\pi}^{\theta-1} E_{t} \widehat{\pi}_{t+1}+\alpha \beta \bar{\pi}^{\theta-1} E_{t}\left(\bar{\pi}_{F_{t+1}}-\widehat{K}_{t+1}\right) \\
& +\alpha \beta \bar{\pi}^{\theta-1}(1-\bar{\pi})\left(u_{c}\left(\widehat{y_{t}-G_{t}}, \zeta_{t}\right)+\widehat{y}_{t}\right)+\left(1-\alpha \beta \bar{\pi}^{\theta}\right) \widehat{m c}_{t}-\left(1-\alpha \beta \bar{\pi}^{\theta-1}\right)\left(\widehat{1-\tau_{t}}\right) .
\end{aligned}
$$

Adding and subtracting $\alpha \beta \bar{\pi}^{\theta-1} E_{t} \widehat{F}_{t+1}$, then using (47) to substitute for $E_{t}\left(\widehat{F}_{t+1}-\widehat{K}_{t+1}\right)$, $\widehat{F}_{t}-\widehat{K}_{t}$ and then for $\widehat{F}_{t+1}$ with (20), results in:

$$
\begin{aligned}
\widehat{\pi}_{t} & =\beta E_{t} \widehat{\pi}_{t+1}+\kappa^{*} \widehat{m c}_{t}+\widehat{F}_{t} \kappa^{*} \frac{(\bar{\pi}-1)}{1-\alpha \beta \bar{\pi}^{\theta}} \\
& +\kappa^{*}\left(u_{c}\left(\widehat{y_{t}-G_{t}}, \zeta_{t}\right)+\widehat{y}_{t}\right) \frac{1-\bar{\pi}}{1-\alpha \beta \bar{\pi}^{\theta}}-\kappa^{*} \frac{1-\alpha \beta \bar{\pi}^{\theta-1}}{1-\alpha \beta \bar{\pi}^{\theta}}\left(\widehat{1-\tau_{t}}\right) .
\end{aligned}
$$




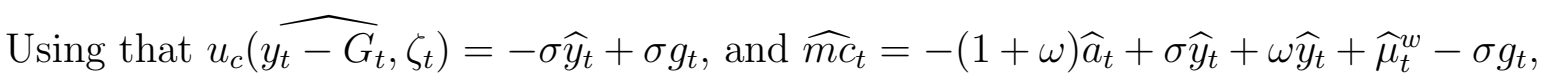
results in

$$
\begin{aligned}
\widehat{\pi}_{t} & =\beta E_{t} \widehat{\pi}_{t+1}+\widehat{F}_{t} \kappa^{*} \frac{(\bar{\pi}-1)}{1-\alpha \beta \bar{\pi}^{\theta}}+\kappa^{*} \widehat{y}_{t}\left[\sigma+\omega+\frac{(1-\bar{\pi})(1-\sigma)}{1-\alpha \beta \bar{\pi}^{\theta}}\right] \\
& +\kappa^{*} \sigma g_{t}\left[\frac{1-\bar{\pi}}{1-\alpha \beta \bar{\pi}^{\theta}}-1\right]+\kappa^{*}\left[\widehat{\mu}_{t}^{w}-(1+\omega) \widehat{a}_{t}+w_{\tau} \frac{1-\alpha \beta \bar{\pi}^{\theta-1}}{1-\alpha \beta \bar{\pi}^{\theta}} \widehat{\tau}_{t}\right]
\end{aligned}
$$

Applying the definition of $\widehat{y}_{t}^{n}$ and making use of $\widehat{\tau}_{t}=0$ in this setting, results in (19) in the text.

\subsection{Proof proposition 3}

The period utility function of the average household in equilibrium is given by:

$$
\int_{0}^{1}\left[u\left(y_{t}-G_{t}, \zeta_{t}\right)-v\left(l_{j t}\right)+z\left(m_{t}\right)\right] d j=u\left(y_{t}-G_{t}\right)+z\left(m_{t}\right)-\int_{0}^{1} v\left(l_{j t}\right) d j .
$$

To derive (23) we need to impose, that in the optimal steady state real money balances are sufficiently close to satiation (see Woodford, 2003, Assumption 6.1), the price dispersion associated with optimal inflation is sufficiently small, as well as that optimal inflation is close enough to one.

The first summand can be approximated to second order by:

$$
\begin{aligned}
u\left(y_{t}-G_{t}, \zeta_{t}\right) & =u+u_{c}\left(y_{t}-y\right)+0.5 u_{c c}\left(y_{t}-y\right)^{2}+u_{c G}\left(y_{t}-y\right)\left(G_{t}-G\right)+u_{c \zeta}\left(y_{t}-y\right)\left(\zeta_{t}-\zeta\right) \\
& +0.5 u_{G G}\left(G_{t}-G\right)^{2}+0.5 u_{\zeta \zeta}\left(\zeta_{t}-\zeta\right)^{2}+\mathcal{O}\left(\left\|\widehat{\xi}_{t}, \widehat{y}_{t}\right\|^{3}\right) \\
& =u_{c}\left(\widehat{y}_{t}+0.5 \widehat{y}_{t}^{2}\right) y+0.5 u_{c c}\left(\widehat{y}_{t}+0.5 \widehat{y}_{t}^{2}\right)^{2} y^{2}+u_{c} \widehat{y}_{t} \widehat{z}_{t} y \\
& -u_{c c} y\left(G_{t}-G\right) \widehat{y}_{t}+\text { t.i.s.p. }+\mathcal{O}\left(\left\|\widehat{\xi}_{t}, \widehat{y}_{t}\right\|^{3}\right) \\
& =u_{c} y\left[\widehat{y}_{t}+\frac{(1-\sigma)}{2} \widehat{y}_{t}^{2}+\sigma g_{t} \widehat{y}_{t}\right]+\text { t.i.s.p. }+\mathcal{O}\left(\left\|\widehat{\xi}_{t}, \widehat{y}_{t}\right\|^{3}\right)
\end{aligned}
$$


where we used that $\left(x_{t}-x\right)=x\left(\widehat{x}_{t}+0.5 \widehat{x}_{t}^{2}\right)+\mathcal{O}\left(\left\|\widehat{x}_{t}\right\|^{3}\right)$, t.i.s.p denotes terms independent of stabilization policy, $u_{c \zeta}=u_{c}, \zeta=1, \sigma=\sigma_{c} s c^{-1}, \widehat{G}_{t}=\left(G_{t}-G\right) / y$, and that $g_{t}=\widehat{G}_{t}+\sigma^{-1} \widehat{\zeta}_{t}$. The utility of real money balances can be approximated by:

$$
z(m)=u_{c} y\left[\frac{z_{m} m}{u_{c} y} \widehat{m}_{t}+0.5 \frac{z_{m} m}{u_{c} y}\left(1-\sigma_{m}\right) \widehat{m}_{t}^{2}\right]+\text { t.i.s.p. }+\mathcal{O}\left(\left\|\widehat{m}_{t}\right\|^{3}\right) .
$$

Following Woodford (2003a), we treat $(R-1) / R$ as an expansion parameter, implying that $z_{m} / u_{c}-0=(R-1) / R-0$ is at least of first order. Since we expand our model at a point near the zero bound, since means, that real money balances are near the satiation level.

Applying an first order approximation to the money demand equation results in $\widehat{m}_{t}=\sigma / \sigma_{m}\left(\widehat{y}_{t}-g_{t}\right)-\left[(R-1) \sigma_{m}\right]^{-1} \widehat{R}_{t}+\mathcal{O}\left(\left\|\widehat{\xi}_{t}\right\|^{2}\right)$. Therefore, the coefficient $\sigma / \sigma_{m}=$ $u_{c c} y(R-1) /\left(R z_{m m} m\right)$ is of first order in $(R-1) / R$. Defining $s_{m}=z_{m} m /\left(u_{c} y\right)$, which is of first order in $(R-1) / R$, so that $s_{m} \sigma / \sigma_{m}$ is of second order, the approximation of $z(m)$ can be rewritten as:

$$
\begin{aligned}
z\left(m_{t}\right) & =u_{c} y\left[s_{m}\left(\frac{\sigma}{\sigma_{m}}\left(\widehat{y}_{t}-g_{t}\right)-\frac{\widehat{R}_{t}}{(R-1) \sigma_{m}}\right)+0.5 s_{m}\left(\frac{\sigma}{\sigma_{m}}\left(\widehat{y}_{t}-g_{t}\right)-\frac{\widehat{R}_{t}}{(R-1) \sigma_{m}}\right)^{2}\right. \\
& \left.-0.5 s_{m} \sigma_{m}\left(\frac{\sigma}{\sigma_{m}}\left(\widehat{y}_{t}-g_{t}\right)-\frac{\widehat{R}_{t}}{(R-1) \sigma_{m}}\right)^{2}\right]+t . i . s . p .+\mathcal{O}\left(\left\|\widehat{\xi}_{t}, \widehat{y}_{t}, \widehat{R}_{t}\right\|^{3}\right) \\
& =u_{c} y\left[-s_{m}\left(\frac{\widehat{R}_{t}}{(R-1) \sigma_{m}}\right)-0.5 \frac{(R-1) \sigma_{m}}{y / m}\left(\frac{\widehat{R}_{t}}{(R-1) \sigma_{m}}\right)^{2}\right]+\text { t.i.s.p. }+\mathcal{O}\left(\left\|\widehat{\xi}_{t}, \widehat{y}_{t}, \widehat{R}_{t}\right\|^{3}\right) \\
& =-u_{c} y \frac{1}{2 \sigma_{m}(R-1) v}\left(\widehat{R}_{t}+(R-1) / R\right)^{2}+t . i . s . p .+\mathcal{O}\left(\left\|\widehat{\xi}_{t}, \widehat{y}_{t}, \widehat{R}_{t}\right\|^{3}\right) \\
& =-u_{c} y \frac{1}{2 \sigma_{m}(R-1) v} \widehat{R}_{t}^{2}+\text { t.i.s.p. }+\mathcal{O}\left(\left\|\widehat{\xi}_{t}, \widehat{y}_{t}, \widehat{R}_{t}\right\|^{3}\right) .
\end{aligned}
$$

In the first step we used that the second term in the first line is of third order. In 
addition we used that

$$
-\frac{1}{(R-1) \sigma_{m}}=\frac{u_{c}}{z_{m m} m}\left(1-\frac{R-1}{R}\right)=\frac{u_{c}}{z_{m m} m}
$$

if $(R-1) / R$ is small. Then it follows that,

$$
-0.5 s_{m} \sigma_{m}=0.5 \frac{z_{m} m}{u_{c} y} \frac{z_{m m} m}{z_{m}}=0.5 \frac{z_{m m} m}{u_{c}} \frac{1}{\frac{y}{m}}=-0.5 \frac{(R-1) \sigma_{m}}{v} .
$$

The last step follows, if one takes into account that $(R-1) / R-0$ is of second order, implying that the linear term drops out in the quadratic approximation. In equilibrium, each household supplies the identical amount of labor, since not a special type of labor, but a bundle of labor types is used as an input factor in production:

$$
\int_{0}^{1} v\left(l_{j t}\right) d j=\int_{0}^{1} v\left(l_{t}\right) d j=v\left(\int_{0}^{1} l_{i t} d i\right)=v\left(\frac{y_{t} \Delta_{t}}{a_{t}}\right)=v\left(y_{t}, \Delta_{t}, a_{t}\right)
$$

This term can be approximated to second order by:

$$
\begin{aligned}
v\left(\frac{y_{t} \Delta_{t}}{a_{t}}\right) & =v+v_{y}\left(y_{t}-y\right)+0.5 v_{y y}\left(y_{t}-y\right)^{2}+v_{y \Delta}\left(y_{t}-y\right)\left(\Delta_{t}-\Delta\right)+v_{y a}\left(y_{t}-y\right)\left(a_{t}-a\right) \\
& +0.5 v_{a a}\left(a_{t}-a\right)^{2}+v_{\Delta}\left(\Delta_{t}-\Delta\right)+v_{a \Delta}\left(a_{t}-a\right)\left(\Delta_{t}-\Delta\right)+0.5 v_{\Delta \Delta}\left(\Delta_{t}-\Delta\right)^{2}+\mathcal{O}\left(\| \widehat{\xi}_{t}, \widehat{y}_{t}, \widehat{\Delta}\right.
\end{aligned}
$$

In accordance with our numerical results we assume that $\left(P_{i} / P\right)^{-\theta}=(\breve{P} / P)^{-\theta}-1=$ $\mathcal{O}\left(\|\varsigma\|^{3}\right)$. Here $\breve{P}$ denotes the average long-term individual price and we collect in $\varsigma$ the distortions of the relative price due to price dispersion in the optimal steady state. Therefore, a second order approximation of $\left(P_{i t} / P_{t}\right)^{-\theta}$ in $\ln \left(P_{i t} / P_{t}\right)=\widehat{p_{i t}}$ results in:

$$
\begin{aligned}
\left(\frac{P_{i t}}{P_{t}}\right)^{-\theta} & =1+\mathcal{O}\left(\|\varsigma\|^{3}\right)-\theta\left(1+\mathcal{O}\left(\left\|\widehat{\xi}_{t}, \varsigma\right\|^{3}\right)\right) \widehat{p_{i t}}+\theta^{2} 0.5\left(1+\mathcal{O}\left(\left\|\widehat{\xi}_{t}, \varsigma\right\|^{3}\right)\right){\widehat{p_{i t}}}^{2}+\mathcal{O}\left(\left\|\widehat{p}_{i t}\right\|^{3}\right) \\
& =1-\theta \widehat{p_{i t}}+\theta^{2} 0.5{\widehat{p_{i t}}}^{2}+\mathcal{O}\left(\left\|\widehat{p}_{i t}, \widehat{\xi}_{t}, \varsigma\right\|^{3}\right) .
\end{aligned}
$$


Integrating this expression across all firms leads to

$$
\Delta_{t}=1-\theta E_{i} \widehat{p}_{i t}+\theta^{2} E_{i} \widehat{p}_{i t}^{2}
$$

Note that a first second order approximation of the price level in $\widehat{p_{i t}}$ results in $E_{i} \widehat{p_{i t}}=$ $\frac{\theta-1}{2} E_{i}{\widehat{p_{i t}}}^{2}$. Using this the dispersion measure can be written as:

$$
\Delta_{t}=1+\frac{\theta}{2} \operatorname{var}_{i} \ln \left(P_{i t}\right)+\mathcal{O}\left(\left\|\widehat{p}_{i t}, \widehat{\xi}_{t}, \varsigma\right\|^{3}\right)
$$

and is of second order. That implies, since $\Delta_{t}-\Delta=\Delta_{t}-1+\mathcal{O}\left(\|\varsigma\|^{3}\right)=\Delta \widehat{\Delta_{t}}+\mathcal{O}\left(\left\|\widehat{\Delta}_{t}^{2}\right\|\right)$, that $\widehat{\Delta}_{t}$ is of second order, too. It follows that the second order approximation of $v\left(l_{t}\right)$ can be rewritten as:

$$
v\left(l_{t}\right)=v_{y} y\left[\widehat{y}_{t}+\frac{1+\omega}{2} \widehat{y}_{t}^{2}-(1+\omega) \widehat{a}_{t} \widehat{y}_{t}+\widehat{\Delta}_{t}\right]+t . i . s . p .+\mathcal{O}\left(\left\|\widehat{\xi}_{t}, \widehat{y}_{t}, \widehat{\Delta}_{t}^{0.5}, \varsigma\right\|^{3}\right),
$$

$v_{y} y=v_{\Delta} \Delta=v_{l} l$. Note that we can connect (51),(52) and (54) by the relationship $v_{y} / u_{c}=a m c / \mu^{w}=(1-\phi)$, with

$$
\phi=1-\rho(\pi)^{\frac{1}{1-\theta}}(1-\tau) \frac{\theta-1}{\mu^{w} \theta} \frac{1-\alpha \beta \pi^{\theta}}{1-\alpha \beta \pi^{\theta-1}} .
$$

This results in:

$$
\begin{aligned}
U\left(c_{t}, l_{t}, m_{t}\right) & =-u_{c} y\left[-\phi \widehat{y}_{t}+\frac{\sigma+\omega-\phi(1+\omega)}{2} \widehat{y}_{t}^{2}-\widehat{y}_{t}\left(\sigma g_{t}+(1-\phi)(1+\omega) \widehat{a}_{t}\right)\right. \\
& \left.+(1-\phi) \frac{\theta}{2} v r_{i} \ln \left(P_{i t}\right)+\frac{1}{2 \sigma_{m}(R-1) v} \widehat{R}_{t}^{2}\right]+t . i . s . p .+\mathcal{O}\left(\left\|\widehat{\xi}_{t}, \varsigma\right\|^{3}\right)
\end{aligned}
$$

Using the sales tax as a sales subsidy by setting

$$
1-\tau=\left[\rho(\pi)^{\frac{1}{1-\theta}} \frac{\theta-1}{\mu^{w} \theta} \frac{1-\alpha \beta \pi^{\theta}}{1-\alpha \beta \pi^{\theta-1}}\right]^{-1}
$$


, the linear term in the welfare approximation above vanishes, so that we get indeed a welfare measure accurate to second order of the true non-linear optimal solution using only linear approximations to the model's structural equations (Woodford, 2003):

$$
\begin{aligned}
U(t) & =-\frac{u_{c} y}{2}\left[(\sigma+\omega)\left(\widehat{y}_{t}-\frac{\sigma g_{t}+(1+\omega) \widehat{a}_{t}}{\sigma+\omega}\right)^{2}+\theta \operatorname{var}_{i} \ln \left(P_{i t}\right)+\frac{\widehat{R}_{t}^{2}}{\sigma_{m}(R-1) v}\right]+\text { t.i.s.p. }+\mathcal{O}\left(\left\|\widehat{\xi}_{t}, \varsigma\right\|^{3}\right) \\
& =-\frac{u_{c} y}{2}\left[(\sigma+\omega)\left(\widehat{y}_{t}-\widehat{y}_{t}^{*}\right)^{2}+\theta v a r_{i} \ln \left(P_{i t}\right)+\frac{1}{\sigma_{m}(R-1) v} \widehat{R}_{t}^{2}\right]+\text { t.i.s.p. }+\mathcal{O}\left(\left\|\widehat{\xi}_{t}, \varsigma\right\|^{3}\right) .
\end{aligned}
$$

The variance of $\ln \left(P_{t}(i)\right)$ follows:

$$
\begin{aligned}
\operatorname{var}_{i}\left(\ln P_{i t}\right) & =\operatorname{\alpha var}_{i}\left(\ln P_{i t-1}\right)+\frac{\alpha}{1-\alpha}\left[\ln \frac{P_{t}}{P_{t-1}}\right]^{2}+\mathcal{O}\left(\left\|\widehat{\xi}_{t}\right\|^{3}\right) \\
& =\alpha \operatorname{var}_{i} \ln \left(P_{i t-1}\right)+\frac{\alpha}{1-\alpha}\left[\ln \left(\pi_{t}\right)-\ln (\pi)\right]\left[\widehat{\pi}_{t}+2 \ln (\pi)\right]+\text { t.i.s.p. }+\mathcal{O}\left(\left\|\widehat{\xi}_{t}\right\|^{3}\right) \\
& =\alpha \operatorname{var}_{i} \ln \left(P_{i t-1}\right)+\frac{\alpha}{1-\alpha}\left[\widehat{\pi}_{t}^{2}+2 \ln (\pi) \widehat{\pi}_{t}\right]+\text { t.i.s.p. }+\mathcal{O}\left(\left\|\widehat{\xi}_{t}\right\|^{3}\right) \\
& =\operatorname{\alpha var}_{i} \ln \left(P_{i t-1}\right)+\frac{\alpha}{1-\alpha} \widehat{\pi}_{t}^{2}+\text { t.i.s.p. }+\mathcal{O}\left(\left\|\widehat{\xi}_{t}, \varsigma^{2 / 3}\right\|^{3}\right),
\end{aligned}
$$

where we assumed that $\ln (\pi)=0+\mathcal{O}\left(\|\varsigma\|^{2}\right)$. Iterating the equation above forward starting from any $\operatorname{var}_{i} \ln \left(P_{i t_{0}-1}\right)$ in the period before policy applies, for $t \geq t_{0}$ results in :

$$
\operatorname{var}_{i} \ln \left(P_{i t}\right)=\sum_{s=t_{0}}^{t} \alpha^{t-s} \frac{\alpha}{1-\alpha} \widehat{\pi}_{s}^{2}+\text { t.i.s.p. }+\mathcal{O}\left(\left\|\widehat{\xi}_{t}, \varsigma^{2 / 3}\right\|^{3}\right),
$$

where we used that the initial price dispersion $\operatorname{var}_{i} \ln \left(P_{i t_{0}-1}\right)$ is t.i.s.p.

Discounting this expression with $\beta$ and summing up gives

$$
\sum_{t=t_{0}}^{\infty} \beta^{t-t_{0}} \operatorname{var}_{i}\left(\ln P_{i t}\right)=\frac{\alpha}{(1-\alpha)(1-\alpha \beta)} \sum_{t=t_{0}}^{\infty} \beta^{t-t_{0}} \widehat{\pi}_{t}^{2}+t . i . s . p .+\mathcal{O}\left(\left\|\widehat{\xi}_{t}, \varsigma\right\|^{3}\right) .
$$

Applying this result to (55) gives (23) in proposition 3. 


\subsection{Definition of the disturbances $n_{t}, u_{t}$ and $s_{t}$}

The exogenous fluctuations are defines as:

$$
\begin{gathered}
n_{t}=\eta_{2} E_{t}\left(\widehat{a}_{t+1}-\widehat{a}_{t}\right)-\eta_{1} \sigma E_{t}\left(g_{t+1}-g_{t}\right), \\
u_{t}=\eta_{3} \widehat{a}_{t}+\left(1-\alpha \beta \bar{\pi}^{\theta}\right) \widehat{\mu}_{t}^{w}+\eta_{3} \sigma g_{t}
\end{gathered}
$$

and

$$
s_{t}=\eta_{5} \widehat{a}_{t}+\eta_{6} \sigma g_{t}+\kappa^{*} \widehat{\mu}_{t}^{w}
$$

The constants $\eta_{i}, i=1, . .6$ are defined as:

$$
\begin{gathered}
\eta_{1}=\frac{\omega}{\omega+\sigma}, \\
\eta_{2}=\frac{\sigma(1+\omega)}{\omega+\sigma}, \\
\eta_{3}=\left(1-\alpha \beta \bar{\pi}^{\theta}\right)(1+\omega) \frac{1-\sigma}{\omega+\sigma}, \\
\eta_{4}=\kappa^{*}\left[\omega+\sigma+\frac{(1-\bar{\pi})(1-\sigma)}{1-\alpha \beta \bar{\pi}^{\theta}}\right], \\
\eta_{5}=\frac{\eta_{4}(1+\omega)}{\omega+\sigma}-\kappa^{*}(1+\omega)
\end{gathered}
$$

and

$$
\eta_{6}=\frac{\eta_{4}}{\omega+\sigma}+\kappa^{*}\left(\frac{1-\bar{\pi}}{1-\alpha \beta \bar{\pi}^{\theta}}-1\right) .
$$




\section{Additional figures and tables}

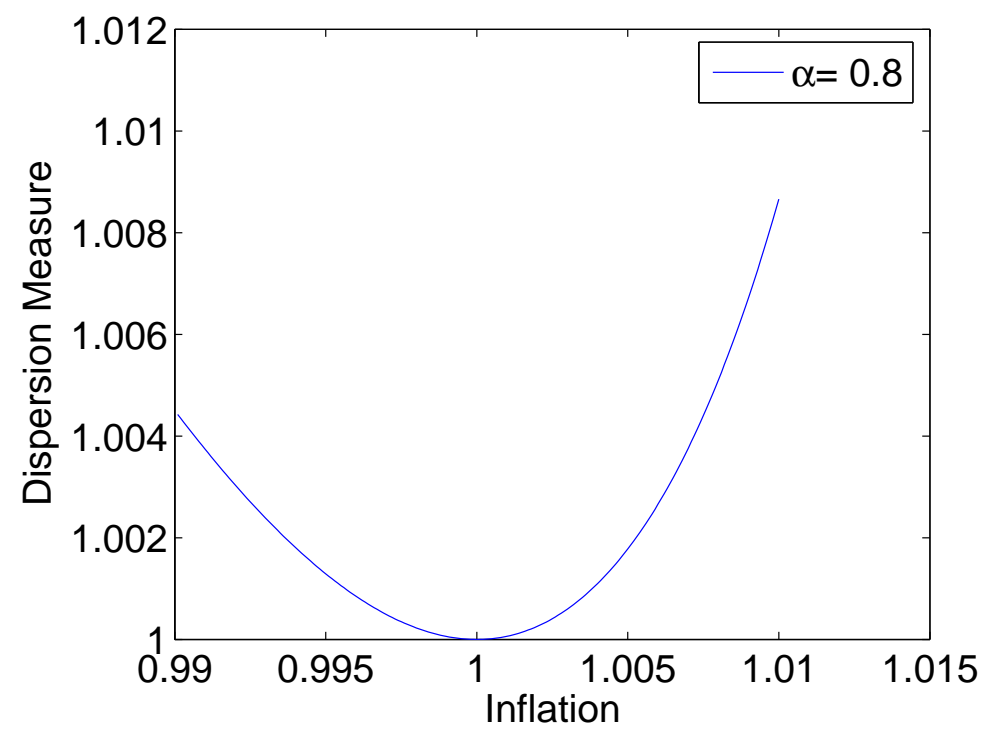

Figure 4: Steady state price dispersion as a function of inflation.

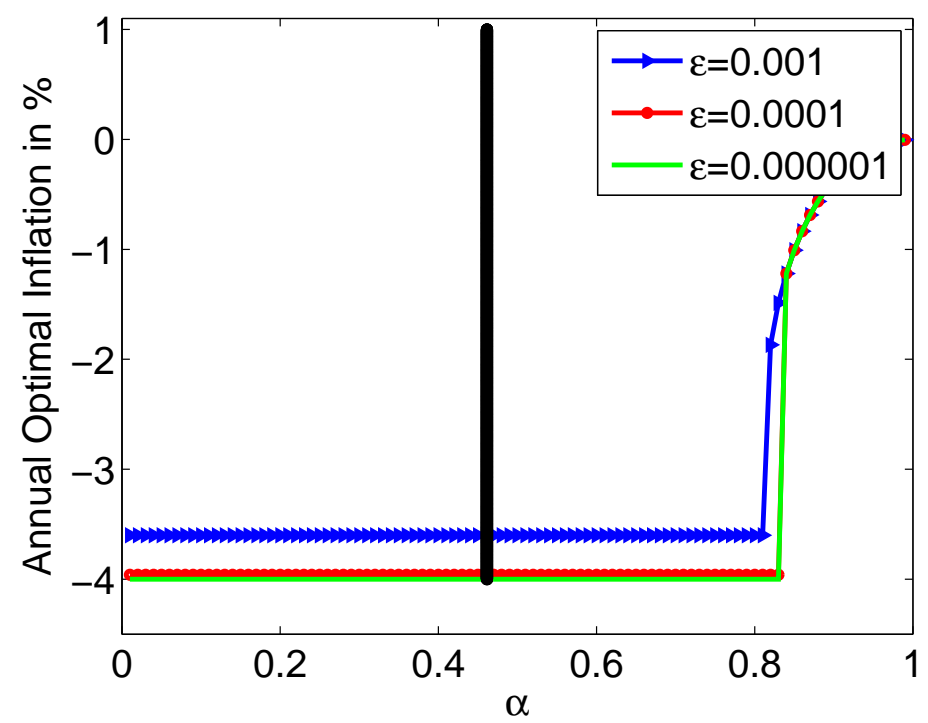

Figure 5: Optimal annual inflation and Calvo parameter $\alpha$. The vertical line denotes the critical value in Schmitt-Grohe and Uribe (2005) for which the Friedman rule ceases to be optimal. 


\begin{tabular}{ccccccc}
\hline$a_{1}$ & $\lambda_{R}^{Z E R O}$ & $\lambda_{R}^{F R}$ & $100 *\left(L_{Z E R O}-L_{F R}\right) / L_{F R}$ & $100 * d U / U$ & $\sigma(\mathrm{FR})$ & $\sigma(Z E R O)$ \\
\hline $1 / 20$ & 2.3426 & 928920 & 32.29 & 0.80 & 1999 & 41 \\
$1 / 50$ & 1.6238 & 643870 & 20.25 & 0.53 & 1386 & 31 \\
$1 / 99$ & 1.2355 & 488930 & 10.12 & 0.38 & 1054 & 25 \\
$1 / 150$ & 1.0463 & 414910 & 3.60 & 0.27 & 893 & 23 \\
$1 / 189$ & 0.9539 & 378270 & -0.12 & 0.23 & 814 & 21 \\
$1 / 250$ & 0.8530 & 338230 & -4.68 & 0.15 & 728 & 20 \\
$1 / 500$ & 0.6464 & 256330 & -16.10 & 0.09 & 552 & 17 \\
$1 / 1000$ & 0.4899 & 19460 & -27.38 & 0.02 & 418 & 15 \\
\hline
\end{tabular}

Table 3: Welfare Analysis: $\epsilon=0.000001$ 


\section{References}

Andrés, J., J.D. López-Salido and J. Vallés, 2006, Money in an Estimated Business Cycle Model of the Euro Area, Economic Journal, vol. 116, 457-477.

Ascari, G., 2004, Staggered Prices and Trend Inflation: Some Nuisances, Review of Economic Dynamics ,vol. 7, pp. 642-667.

Ascari, G., and T. Ropele, 2004, The Optimal Stability-Oriented Monetary Policy: Optimal Monetary Policy Under Low Trend Inflation, Working Paper.

Benigno, P. and M. Woodford, 2005, Inflation Stabilization and Welfare: The Case of a Distorted Steady State, Journal of the European Economic Association, vol. $3,1185-1236$.

Calvo, G.A., 1983, Staggered prices in a Utility-Maximizing Framework, Journal of Monetary Economics, vol. 12, 383-398.

Ireland, P.N., 2004, Money's Role in the Monetary Business Cycle, Journal of Money Credit and Banking, vol. 36, 969-983.

Khan, A., R.G. King and A.L. Wolman, 2003, Optimal Monetary Policy, Review of Economic Studies, vol. 70, 825-860.

Kiley, M. T. 2002, Partial Adjustment and Staggered Price Setting, Journal of Money, Credit, and Banking, vol. 34, 283 - 298.

Levin, A., A. Onatski, J. Williams, and N. Williams, 2005, Monetary Policy under Uncertainty in Microfounded Macroeconometric Models. In: NBER Macroeconomics Annual 2005, Gertler, M., and K. Rogoff, eds. Cambridge, MA: MIT Press. 
Lucas, R., 2000, Inflation and Welfare, Econometrica, vol. 68, 247 - 274.

Rotemberg, J.J. and M. Woodford, 1999, Interest-Rate-Rules in an Estimated StickyPrice-Model, in J.B. Taylor, ed., Monetary Policy Rules, Chicago: University of Chicago Press.

Schmitt-Grohé, S., and M. Uribe, 2004, Optimal Fiscal and Monetary Policy under Sticky Prices, Journal of Economic Theory, vol. 114, 198-230.

Schmitt-Grohé, S., and M. Uribe, 2005, Optimal Inflation Stabilization in a MediumScale Macroeconomic Model, NBER Working Paper No. 11854.

Sidrauski, M., 1967, Rational Choice and Patterns of Growth in a Monetary Economy, American Economic Review, vol. 57, 534-544.

Walsh, C., 2003, Monetary Theory and Policy, second edition, Cambridge: MIT Press.

Walsh, C., 2005, Parameter Misspecification and Robust Monetary Policy Rules, ECB Working Paper No.477.

Woodford, M., 2003a, Interest and Prices: Foundations of a Theory of Monetary Policy, Princeton: Princeton University Press.

Woodford, M., 2003b, Optimal Interest Rate Smoothing, Review of Economic Studies, 70, 861-886. 


\section{SFB 649 Discussion Paper Series 2006}

For a complete list of Discussion Papers published by the SFB 649, please visit http://sfb649.wiwi.hu-berlin.de.

001 "Calibration Risk for Exotic Options" by Kai Detlefsen and Wolfgang K. Härdle, January 2006.

002 "Calibration Design of Implied Volatility Surfaces" by Kai Detlefsen and Wolfgang K. Härdle, January 2006.

003 "On the Appropriateness of Inappropriate VaR Models" by Wolfgang Härdle, Zdeněk Hlávka and Gerhard Stahl, January 2006.

004 "Regional Labor Markets, Network Externalities and Migration: The Case of German Reunification" by Harald Uhlig, January/February 2006.

005 "British Interest Rate Convergence between the US and Europe: A Recursive Cointegration Analysis" by Enzo Weber, January 2006.

006 "A Combined Approach for Segment-Specific Analysis of Market Basket Data" by Yasemin Boztuğ and Thomas Reutterer, January 2006.

007 "Robust utility maximization in a stochastic factor model" by Daniel Hernández-Hernández and Alexander Schied, January 2006.

008 "Economic Growth of Agglomerations and Geographic Concentration of Industries - Evidence for Germany" by Kurt Geppert, Martin Gornig and Axel Werwatz, January 2006.

009 "Institutions, Bargaining Power and Labor Shares" by Benjamin Bental and Dominique Demougin, January 2006.

010 "Common Functional Principal Components" by Michal Benko, Wolfgang Härdle and Alois Kneip, Jauary 2006.

011 "VAR Modeling for Dynamic Semiparametric Factors of Volatility Strings" by Ralf Brüggemann, Wolfgang Härdle, Julius Mungo and Carsten Trenkler, February 2006.

012 "Bootstrapping Systems Cointegration Tests with a Prior Adjustment for Deterministic Terms" by Carsten Trenkler, February 2006.

013 "Penalties and Optimality in Financial Contracts: Taking Stock" by Michel A. Robe, Eva-Maria Steiger and Pierre-Armand Michel, February 2006.

014 "Core Labour Standards and FDI: Friends or Foes? The Case of Child Labour" by Sebastian Braun, February 2006.

015 "Graphical Data Representation in Bankruptcy Analysis" by Wolfgang Härdle, Rouslan Moro and Dorothea Schäfer, February 2006.

016 "Fiscal Policy Effects in the European Union" by Andreas Thams, February 2006.

017 "Estimation with the Nested Logit Model: Specifications and Software Particularities" by Nadja Silberhorn, Yasemin Boztuğ and Lutz Hildebrandt, March 2006.

018 "The Bologna Process: How student mobility affects multi-cultural skills and educational quality" by Lydia Mechtenberg and Roland Strausz, March 2006.

019 "Cheap Talk in the Classroom" by Lydia Mechtenberg, March 2006.

020 "Time Dependent Relative Risk Aversion" by Enzo Giacomini, Michael Handel and Wolfgang Härdle, March 2006.

021 "Finite Sample Properties of Impulse Response Intervals in SVECMs with Long-Run Identifying Restrictions" by Ralf Brüggemann, March 2006.

022 "Barrier Option Hedging under Constraints: A Viscosity Approach" by Imen Bentahar and Bruno Bouchard, March 2006.

\section{SFB 649, Spandauer Straße 1, D-10178 Berlin} http:/ / sfb649.wiwi.hu-berlin.de

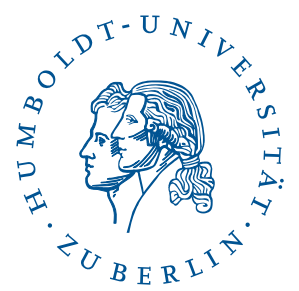


023 "How Far Are We From The Slippery Slope? The Laffer Curve Revisited" by Mathias Trabandt and Harald Uhlig, April 2006.

024 "e-Learning Statistics - A Selective Review" by Wolfgang Härdle, Sigbert Klinke and Uwe Ziegenhagen, April 2006.

025 "Macroeconomic Regime Switches and Speculative Attacks" by Bartosz Maćkowiak, April 2006.

026 "External Shocks, U.S. Monetary Policy and Macroeconomic Fluctuations in Emerging Markets" by Bartosz Maćkowiak, April 2006.

027 "Institutional Competition, Political Process and Holdup" by Bruno Deffains and Dominique Demougin, April 2006.

028 "Technological Choice under Organizational Diseconomies of Scale" by Dominique Demougin and Anja Schöttner, April 2006.

029 "Tail Conditional Expectation for vector-valued Risks" by Imen Bentahar, April 2006.

030 "Approximate Solutions to Dynamic Models - Linear Methods" by Harald Uhlig, April 2006.

031 "Exploratory Graphics of a Financial Dataset" by Antony Unwin, Martin Theus and Wolfgang Härdle, April 2006.

032 "When did the 2001 recession really start?" by Jörg Polzehl, Vladimir Spokoiny and Cătălin Stărică, April 2006.

033 "Varying coefficient GARCH versus local constant volatility modeling. Comparison of the predictive power" by Jörg Polzehl and Vladimir Spokoiny, April 2006.

034 "Spectral calibration of exponential Lévy Models [1]" by Denis Belomestny and Markus Reiß, April 2006.

035 "Spectral calibration of exponential Lévy Models [2]" by Denis Belomestny and Markus Reiß, April 2006.

036 "Spatial aggregation of local likelihood estimates with applications to classification" by Denis Belomestny and Vladimir Spokoiny, April 2006.

037 "A jump-diffusion Libor model and its robust calibration" by Denis Belomestny and John Schoenmakers, April 2006.

038 "Adaptive Simulation Algorithms for Pricing American and Bermudan Options by Local Analysis of Financial Market" by Denis Belomestny and Grigori N. Milstein, April 2006.

039 "Macroeconomic Integration in Asia Pacific: Common Stochastic Trends and Business Cycle Coherence" by Enzo Weber, May 2006.

040 "In Search of Non-Gaussian Components of a High-Dimensional Distribution" by Gilles Blanchard, Motoaki Kawanabe, Masashi Sugiyama, Vladimir Spokoiny and Klaus-Robert Müller, May 2006.

041 "Forward and reverse representations for Markov chains" by Grigori N. Milstein, John G. M. Schoenmakers and Vladimir Spokoiny, May 2006.

042 "Discussion of 'The Source of Historical Economic Fluctuations: An Analysis using Long-Run Restrictions' by Neville Francis and Valerie A. Ramey" by Harald Uhlig, May 2006.

043 "An Iteration Procedure for Solving Integral Equations Related to Optimal Stopping Problems" by Denis Belomestny and Pavel V. Gapeev, May 2006.

044 "East Germany's Wage Gap: A non-parametric decomposition based on establishment characteristics" by Bernd Görzig, Martin Gornig and Axel Werwatz, May 2006.

045 "Firm Specific Wage Spread in Germany - Decomposition of regional differences in inter firm wage dispersion" by Bernd Görzig, Martin Gornig and Axel Werwatz, May 2006.

\section{SFB 649, Spandauer Straße 1, D-10178 Berlin http:/ / sfb649.wiwi.hu-berlin.de}

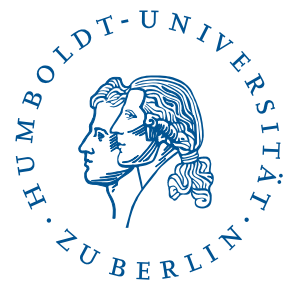


046 "Produktdiversifizierung: Haben die ostdeutschen Unternehmen den Anschluss an den Westen geschafft? - Eine vergleichende Analyse mit Mikrodaten der amtlichen Statistik" by Bernd Görzig, Martin Gornig and Axel Werwatz, May 2006.

047 "The Division of Ownership in New Ventures" by Dominique Demougin and Oliver Fabel, June 2006.

048 "The Anglo-German Industrial Productivity Paradox, 1895-1938: A Restatement and a Possible Resolution" by Albrecht Ritschl, May 2006.

049 "The Influence of Information Costs on the Integration of Financial Markets: Northern Europe, 1350-1560" by Oliver Volckart, May 2006.

050 "Robust Econometrics" by Pavel Čížek and Wolfgang Härdle, June 2006.

051 "Regression methods in pricing American and Bermudan options using consumption processes" by Denis Belomestny, Grigori N. Milstein and Vladimir Spokoiny, July 2006.

052 "Forecasting the Term Structure of Variance Swaps" by Kai Detlefsen and Wolfgang Härdle, July 2006.

053 "Governance: Who Controls Matters" by Bruno Deffains and Dominique Demougin, July 2006.

054 "On the Coexistence of Banks and Markets" by Hans Gersbach and Harald Uhlig, August 2006.

055 "Reassessing Intergenerational Mobility in Germany and the United States: The Impact of Differences in Lifecycle Earnings Patterns" by Thorsten Vogel, September 2006.

056 "The Euro and the Transatlantic Capital Market Leadership: A Recursive Cointegration Analysis" by Enzo Weber, September 2006.

057 "Discounted Optimal Stopping for Maxima in Diffusion Models with Finite Horizon" by Pavel V. Gapeev, September 2006.

058 "Perpetual Barrier Options in Jump-Diffusion Models" by Pavel V. Gapeev, September 2006.

059 "Discounted Optimal Stopping for Maxima of some Jump-Diffusion Processes" by Pavel V. Gapeev, September 2006.

060 "On Maximal Inequalities for some Jump Processes" by Pavel V. Gapeev, September 2006.

061 "A Control Approach to Robust Utility Maximization with Logarithmic Utility and Time-Consistent Penalties" by Daniel Hernández-Hernández and Alexander Schied, September 2006.

062 "On the Difficulty to Design Arabic E-learning System in Statistics" by Taleb Ahmad, Wolfgang Härdle and Julius Mungo, September 2006.

063 "Robust Optimization of Consumption with Random Endowment" by Wiebke Wittmüß, September 2006.

064 "Common and Uncommon Sources of Growth in Asia Pacific" by Enzo Weber, September 2006.

065 "Forecasting Euro-Area Variables with German Pre-EMU Data" by Ralf Brüggemann, Helmut Lütkepohl and Massimiliano Marcellino, September 2006.

066 "Pension Systems and the Allocation of Macroeconomic Risk" by Lans Bovenberg and Harald Uhlig, September 2006.

067 "Testing for the Cointegrating Rank of a VAR Process with Level Shift and Trend Break" by Carsten Trenkler, Pentti Saikkonen and Helmut Lütkepohl, September 2006.

068 "Integral Options in Models with Jumps" by Pavel V. Gapeev, September 2006.

069 "Constrained General Regression in Pseudo-Sobolev Spaces with Application to Option Pricing" by Zdeněk Hlávka and Michal Pešta, September 2006.

\section{SFB 649, Spandauer Straße 1, D-10178 Berlin} http:/ / sfb649.wiwi.hu-berlin.de

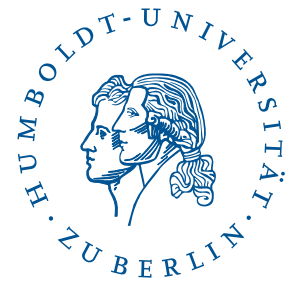


070 "The Welfare Enhancing Effects of a Selfish Government in the Presence of Uninsurable, Idiosyncratic Risk" by R. Anton Braun and Harald Uhlig, September 2006.

071 "Color Harmonization in Car Manufacturing Process" by Anton Andriyashin, Michal Benko, Wolfgang Härdle, Roman Timofeev and Uwe Ziegenhagen, October 2006.

072 "Optimal Interest Rate Stabilization in a Basic Sticky-Price Model" by Matthias Paustian and Christian Stoltenberg, October 2006. 